\title{
A DECISION SUPPORT TOOL FOR PLANNING BIOWASTE MANAGEMENT SYSTEMS
}

\section{ABSTRACT}

Biowaste is one of the predominant fractions in municipal waste. Its easy degradation in the ground causes the emission of polluting gases and generates leachate that pose a great environmental risk. Defining solutions for biowaste management may have multiple varied, sometimes confronted objectives, and involve several linked stages. This article presents a new tool for the planning of biowaste management systems. The tool distinguishes four stages within the waste management line: collection (defined by the separation model and the collection system), pre-treatment, treatment, and application. Several alternatives are considered for each stage. The different combinations of alternatives that define the management systems are evaluated in two phases. First, the compatibility matrix establishes the affinity between the alternatives selected for each stage and then each alternative is assessed using indicators associated with environmental, social, technical and economic criteria. Both management alternatives and criteria considered in the tool can be modified or extended according to the local circumstances. The paper describes a case study that shows the value of the tool as an aid in decision-making for alternative selection in waste management systems under different scenarios and priorities. 


\section{A DECISION SUPPORT TOOL FOR PLANNING BIOWASTE MANAGEMENT SYSTEMS}

\section{Introduction}

"Biowaste" is defined in Directive 2008/98/EC (European Parliament and Council, 2008) as "Biodegradable waste from gardens and parks, food and kitchen waste from homes, restaurants, collective catering services and retail establishments, and comparable waste from food processing plants". Within the category of municipal waste, biowaste (hereafter used synonymously with 'organic fraction') includes food and kitchen waste from homes and small size green waste. This is one of the most problematic fractions, due to the large volume generated and its easy degradability when deposited in the ground. At present, landfill waste disposal is one of the most used techniques, in the majority of countries, for this kind of waste (Kaza et al., 2018; Edwards et al., 2018), as it favors the decomposition of a material that, in many cases, has no use. This decomposition, however, causes the emission of greenhouse gases and the generation of leachate, which can result in serious environmental pollution if they are not collected and treated properly (Gupta and Garg, 2017).

The latest studies, available for 2016, estimate that approximately 2.02 billion tons of industrial and municipal waste are generated worldwide per year, which could reach up to 3.40 trillion tons by the year 2050 (Kaza et al., 2018). Due to population growth, the strong development of the food industry, and new trends in consumption, the amount of biowaste present in urban waste in most developed countries has increased considerably in recent years (Capson-Tojo et al., 2017). According to data from the World Bank, the average worldwide generation of green and food waste represents $44 \%$ of the total waste generated, and is the majority fraction (Kaza et al., 2018).

This kind of waste presents several characteristics that determine its treatment. For example, it is a heterogeneous residue that changes with the habits of the population (Abdullahi et al., 2008), it is unstable due to its composition and high water content (around 70-80\%) (Li et al., 2014), and its density is also variable and high. Currently, the most used treatments for the organic fraction are, first, disposal, followed by aerobic biological treatment for the generation of biostabilized product. In cases where a separate collection system of the organic fraction is implemented, the most common treatment is composting, followed, to a lesser extent, by anaerobic digestion.

In the last few decades, international directives have focused their objectives on preventing the disposal of biowaste in landfills (Pubule et al., 2015), while trying to promote its use by collecting it separately and establishing a hierarchy of actions for its correct management (European Parliament and Council, 2008), among others. This hierarchy is based on: 1) prioritizing the reduction of biowaste production, avoiding food waste and promoting the use of food; 2) giving priority to biological treatments such as composting or anaerobic digestion instead of thermal treatments for energy recovery; and, finally, 3) reducing the disposal of fresh biowaste in landfills. In order to carry out this hierarchy, the sourced segregation collection of biowaste is of great importance. This segregation at source makes it possible to reduce the amount of biowaste intended for final treatments and, due to its low improper content, allows enhanced utilization as a quality organic amendment.

The choice of alternatives for the organic waste management and treatment system is a complex task that requires taking into consideration numerous factors that may vary in each scenario. Many studies have been conducted on different options for municipal waste management systems (Hong et al., 2010; Chan et al., 2011; Milutinović et al., 2014; Goulart Coelho et al., 2017). Some of them are focused on environmental aspects, others on economic ones and, to a lesser extent, some also integrate social and technical aspects. The main limitation of these studies is that they are focused on specific cases (Hong et al., 2010; Santos et al., 2017; $\mathrm{Ng}$ et al., 2017; De Feo et al., 2019) and therefore the methods used are not translatable to other contexts. In addition, 
only a few of them focus on biowaste (Di Maria and Micale, 2015; Lombardi et al., 2015; Vea et al., 2018; Edwards et al., 2018).

This article presents a new tool, created to help decision-making in the process of optimizing the management system of biowaste. The tool may be adapted to particular scenarios, taking into account different alternatives, priorities and circumstances.

\section{Tool general structure}

Figure 1 shows a general outline of the tool, called "DELIGES", developed in this study. The complete biowaste management line is divided into four stages that are defined and assessed separately: collection, pretreatment, treatment and application. Different options may be introduced for each stage, according to the aim of the study. The following paragraphs present the alternatives considered in this work.

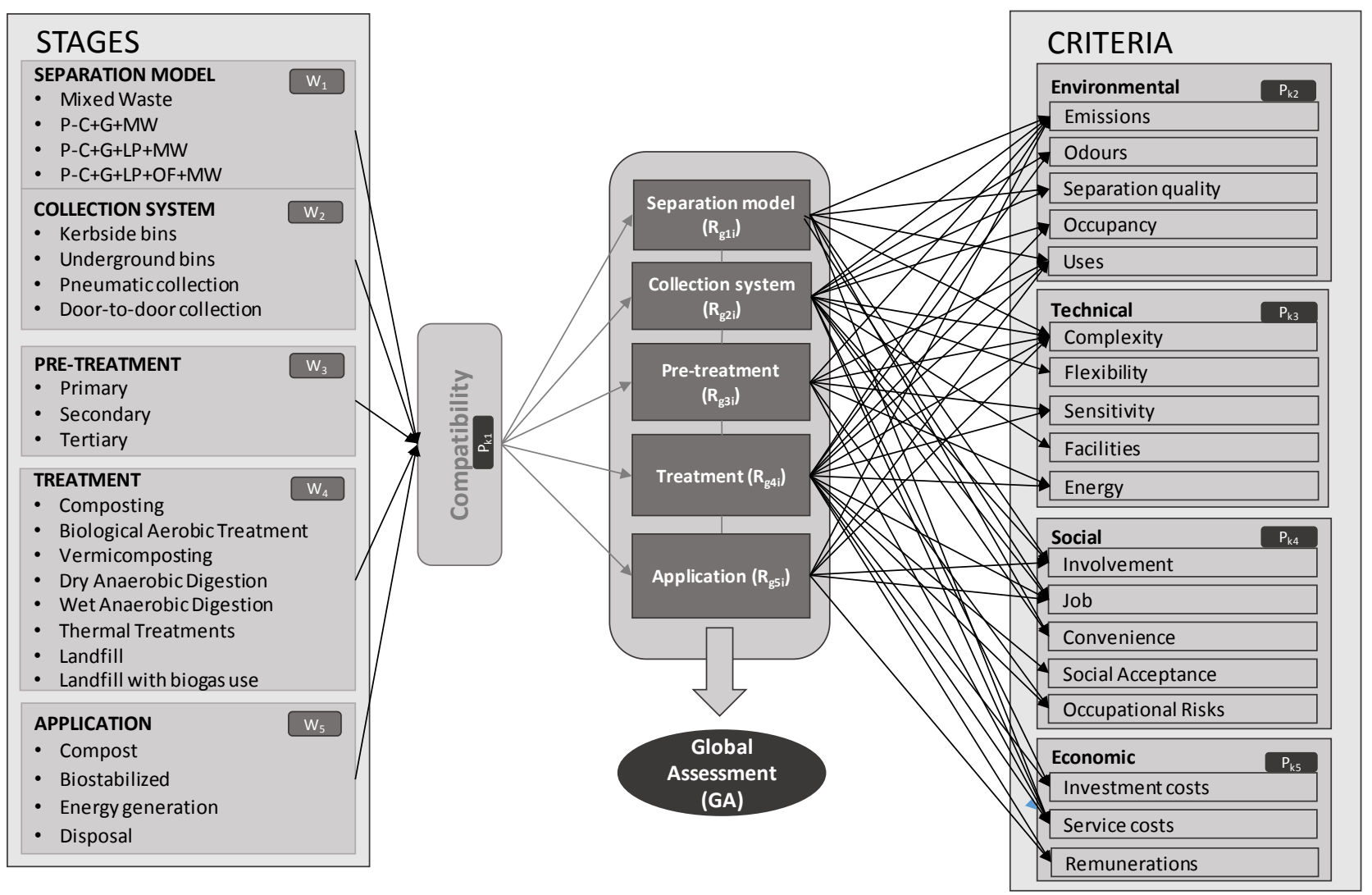

Fig. 1. Scheme of the DELIGES tool structure.

The first stage, collection, includes two components: separation model and collection system. The separation model relates the different waste separation schemes, which determine the compatibility with some of the alternatives of the following stages. Four alternatives have been considered in this work: mixed waste collection; selective with three fractions: paper-cardboard $(P-C)$, glass $(G)$, and mixed waste $(M W),(P-C+G+M W)$; selective with four fractions: $P-C, G$, light packaging (LP), and $M W(P-C+G+L P+M W)$; and selective with five fractions: $P-C, G, L P$, organic fraction (OF), and $M W(P-C+G+L P+O F+M W)$. The collection stage can be determined by the collection system and separation model already implemented in the area to be served, or by the other suitable ones depending on the treatment and the intended subsequent use of the waste. Assuming a containerized system, three collection systems have been considered here: kerbside bins (KB), underground bins (UB), pneumatic collection (PC) and door-to-door collection (DDC).

The second stage is pre-treatment, which has been divided into three sub-stages to make the definition of the combined alternatives more flexible, according to the needs of the subsequent treatment. The primary pretreatment includes a simple triage and a simple improper materials separation (P1-S) (for the source- 
segregated organic fraction) and a triage and an intensive improper materials separation (P1 - I) (for the organic fraction collected mixed with other materials). The secondary pre-treatment comprises the shredding, homogenization and conditioning of the residue (P2 - SH), and the mix with green fraction (P2 - MGF). The alternatives proposed for the tertiary treatment are: pulping (P3 - P) or pulping and pre-hydrolysis (P3 - PP), which can be incorporated before a wet anaerobic digestion; biological pre-treatment (P3 - B) for dry anaerobic digestion or vermicomposting; and drying and pelletizing (P3 - DP), which is useful in the case of a thermal treatment.

The third stage considered is the treatment. This is one of the most important stages of the biowaste management line, since it is strongly linked to the choice of the source-segregation scheme, determines the pretreatments to be carried out and the final use of the product obtained. The treatment alternatives included in this work are: composting (C), biological aerobic treatment (BAT), vermicomposting (VC), dry anaerobic digestion (DAD), wet anaerobic digestion (WAD), incineration (I), gasification $(G)$, pyrolysis (P), landfill without biogas use (L), and landfill with biogas use (LB).

Finally, the final application has been considered. Even though it is the last stage of the management system, it is of primary importance in its definition. It defines the use given to the organic matter once treated and therefore the efficiency of the system for resource recovery, within a Circular Economy scheme. Four basic alternatives have been considered in this study: compost application in soil (CAS), which is only possible if the organic fraction has been sourced segregated; biostabilized material application in soil (BAS), organic amendment of lower quality than compost and with greater restrictions in its use; energy generation (EG); and disposal (D).

For the definition of management systems, two elements, used together, facilitate decision-making: the compatibility matrix and assessment through indicators. The compatibility matrix includes all the stages mentioned above, with the alternatives proposed for each of them, and establishes the compatibility between them. On the other hand, the tool also includes an initial proposal of criteria and indicators and their corresponding assessments, which are the input for a multicriteria analysis method. The alternatives considered as well as the suggested indicators and their score in each case can be modified according to the scenario under study and the priorities.

As a tool for data handling and calculation the computer application DELIGES was built as a means to create and compare biowaste management lines in a simple and efficient way. As a complement, a guide has been developed that includes information on the alternatives for each stage, the description of the compatibility matrix considered, the indicators and assessments given to each alternative, as well as the method used for the multicriteria assessment and the DELIGES user manual.

\section{Compatibility Matrix}

Following the structure of Maurer et al. (2012), the compatibilities between the existing alternatives in the different stages can be organized in a compatibility matrix. Table 1 shows the compatibility matrix created for the stages and alternatives described in the previous section. Compatibility is represented by a simple numerical nomenclature, and it defines the possibility of two options coexisting in the same waste management system. The most favorable combination will always be the one with a degree of compatibility of 1 , while, if compatibility is 0 , the alternatives considered cannot be part of the same management system. Alternatives that have a degree of compatibility of 0.5 can be adopted jointly, but their combination is not the most appropriate option.

The matrix allows a management system to be defined through several steps. To promote the use of waste and obtain environmental, economic and social benefits, the entry in the matrix should be based on the desired final application of the biowaste.

Next, the separation model and collection system are successively defined by choosing among those alternatives that are compatible with the application selected and between them. The treatment is then selected 
to finally establish the necessary pre-treatments in stages I, II and III. These will be defined, in most cases, directly by the compatibility with the chosen treatment. 
Table 1. Compatibility Matrix for the biowaste management alternatives defined in this work.

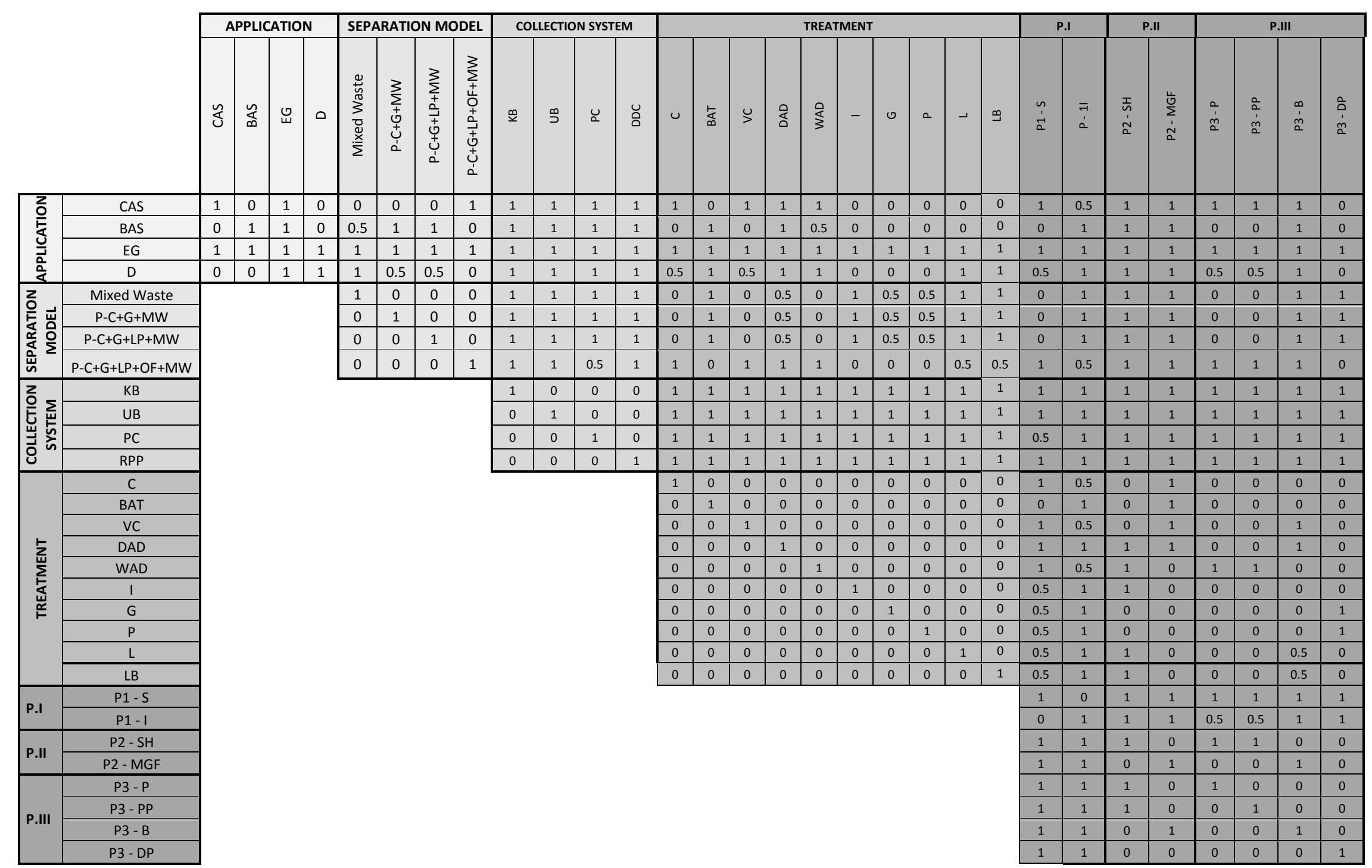




\section{Multicriteria assessment}

The selection of alternatives in the management system must consider technical, but also environmental, economic and social criteria. Here, an assessment of criteria, weighted integration thereof and a weighted aggregation of the stages is proposed to obtain the overall evaluation of the treatment line. For criteria integration, the TOPSIS (Technique for Order of Preference by Similarity to Ideal Solution) method is used (Hwang and Yoon, 1981).

\subsection{Description of the method}

The objective of this method is to help in making decisions with multiple criteria by classifying the alternatives according to the distance that separates them from the ideal solution. To do this, a normalization of the values is performed to compare and order them according to the alternative that most closely approximates the Ideal Positive Solution.

The normalized values $\left(b_{i j}\right)$ are obtained by applying Eq. (1) or Eq. (2), where $x_{i j}$ is the score defined for each of the alternatives (i) for the indicator (j). They are then weighted following Eq. (3).

$$
\begin{aligned}
& \mathrm{b}_{\mathrm{ij}}=\frac{\max x_{i j}-x_{i j}}{\max x_{i j}-\min x_{i j}}, \text { if } \max \mathrm{x}_{\mathrm{ij}} \text { is preferable; } \\
& \mathrm{b}_{\mathrm{ij}}=\frac{x_{i j}-\min x_{i j}}{\max x_{i j}-\min x_{i j}}, \text { if } \min \mathrm{x}_{\mathrm{ij}} \text { is preferable; } \\
& \mathrm{V}_{\mathrm{ij}}=\mathrm{b}_{\mathrm{ij}}{ }^{*} \mathrm{~W}_{\mathrm{ij}}
\end{aligned}
$$

Next, the Ideal Positive and Negative Solution, the best and worst possible rating for the alternatives, are defined. The distance of each alternative to the Ideal Positive $(d+)$ and Negative Solution $(d-)$ is calculated through Eq. (4) and Eq. (5).

Distance to the Ideal Positive Solution:

$$
\mathrm{d}^{+}=\sqrt{\sum_{j=1}^{n}\left(v_{i j}-v_{j}^{+}\right)^{2}}, \mathrm{i}=1,2, \ldots, \mathrm{m}
$$

Distance to the Ideal Negative Solution:

$$
\mathrm{d}^{-}=\sqrt{\sum_{j=1}^{n}\left(v_{i j}-v_{j}^{-}\right)^{2}}, \mathrm{i}=1,2, \ldots, \mathrm{m}
$$

The final calculation is the relative closeness of each alternative to the ideal solution $\left(R_{k s i}\right)$, for each criterion (k) and stage (s), which is defined by Eq. (6):

$$
R_{k s i}=\frac{d_{i}^{+}}{\left(d_{i}^{+}-d_{i}^{-}\right)}, \mathrm{i}=1,2, \ldots, \mathrm{m}
$$

$R_{\mathrm{ksi}}$ is in the range between 0 and 1 , with the best alternative being the one closest to 1 , since this means that it is closer to the ideal alternative.

Figure 1 shows the weights assigned to each stage $\left(W_{s}\right)$ and the weights for each group of indicators (criteria) $\left(P_{\mathrm{ks}}\right) . \mathrm{R}_{\mathrm{gsi}}$ corresponds to the assessment of each alternative $\mathrm{i}$, obtained through the integration of all the criteria, Eq. (7), involving an assessment for each stage s. The global assessment (GA) is obtained by applying Eq. (8), in which a weighted average of each of the selected alternatives is carried out considering the weights of each stage.

$$
\begin{aligned}
& \mathrm{R}_{\mathrm{gsi}}=\sum_{1}^{5} P_{k s} * R_{k s i} \\
& \mathrm{GA}=\sum_{1}^{5} W_{s} * R_{g s i}
\end{aligned}
$$




\subsection{Indicators assessed}

Different indicators have been selected for each of the stages, trying to reflect the main aspects to be evaluated in each criterion considered. Some of the indicators are assessed quantitatively with certain precision based on the units of each indicator found in the literature. The rest of the indicators are assessed using a scale of order of preference from 1 to 4 , except in the "Treatments" stage, where, due to the greater number of alternatives, the rating scale extends to 5 . For this assessment the most favorable value of each indicator is the one closest to unity.

Tables 2 to 6 show the assessment proposed in this work for each indicator within the different stages $\left(\mathrm{x}_{\mathrm{ij}}\right)$ and the assessment of each alternative, which integrates the equal weighted evaluation of all the criteria $\left(R_{g s i}\right)$. Furthermore, Figures 2 to 6 show the overall rating obtained for each alternative according to each criterion $\left(\mathrm{R}_{\mathrm{ksi}}\right)$.

\section{Separation model}

First, for the criterion "Use of organic matter", it is understood that the more separated the organic fraction is, the easier it will be to use it and the fewer losses there will be in the processes of triage and separation (Gallardo et al., 2012). Related to that criterion in the "Separation quality", the greater the separation into fractions is, the higher the quality of the collected waste will be, including the organic fraction (Gallardo et al., 2012).

"Transport Emissions" considers only those attributable to collection, which will be higher the more separated the collection is, since there will be a greater deployment of vehicles with their corresponding emissions. By taking into account the entire cycle of waste management, these this emissions could be offset by the uses given to the organic matter separated at source (Alvarez-Prado et al., 2010).

"Social Involvement" will be greater when more fractions are separated in the system. With more separated fractions, it is expected that citizens will be more involved in the process of managing their own waste, which will lead to greater awareness and this results in a better predisposition towards improved waste management in the future. However, "Convenience to users" is greater with a smaller number of separated fractions, which will lead to citizen participation in making the contribution of waste to the system greater in systems with fewer fractions (Gallardo et al., 2012). This situation may vary depending on environmental education and the awareness of citizens in each region.

Table 2. Assessment of separation model alternatives.

\begin{tabular}{|c|c|c|c|c|c|c|}
\hline Stage & Criteria & Indicators & $\sum_{\Sigma}^{\infty}$ & 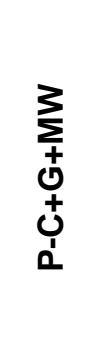 & $\begin{array}{l}\sum_{+}^{3} \\
+ \\
0 \\
+ \\
+ \\
+ \\
+ \\
1 \\
1\end{array}$ & 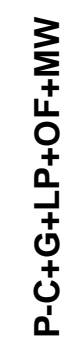 \\
\hline \multirow{8}{*}{ 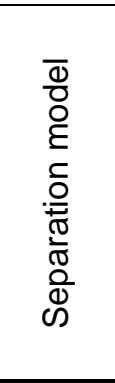 } & \multirow{2}{*}{ Environmental } & Organic matter use & 4 & 3 & 2 & 1 \\
\hline & & Transport emissions & 1 & 2 & 3 & 4 \\
\hline & \multirow{2}{*}{ Technical } & Collection complexity & 1 & 2 & 3 & 4 \\
\hline & & Separation quality & 4 & 3 & 2 & 1 \\
\hline & \multirow{3}{*}{ Social } & Social involvement & 4 & 3 & 2 & 1 \\
\hline & & Job creation & 4 & 3 & 2 & 1 \\
\hline & & Convenience to users & 1 & 2 & 3 & 4 \\
\hline & \multirow[t]{2}{*}{ Economic } & Collection costs & 1 & 2 & 3 & 4 \\
\hline & & & 0.71 & 0.56 & 0.44 & 0.29 \\
\hline
\end{tabular}


${ }^{a}$ MW, Mixed Waste; P-C, Paper-Cardboard; G, Glass; LP, Light Packaging; OF, Organic Fraction.

Even though "Mixed Waste" separation has a better overall assessment for the balanced case, taking into account social or environmental criteria, the case involving five fractions would be the most favorable (Figure 2).

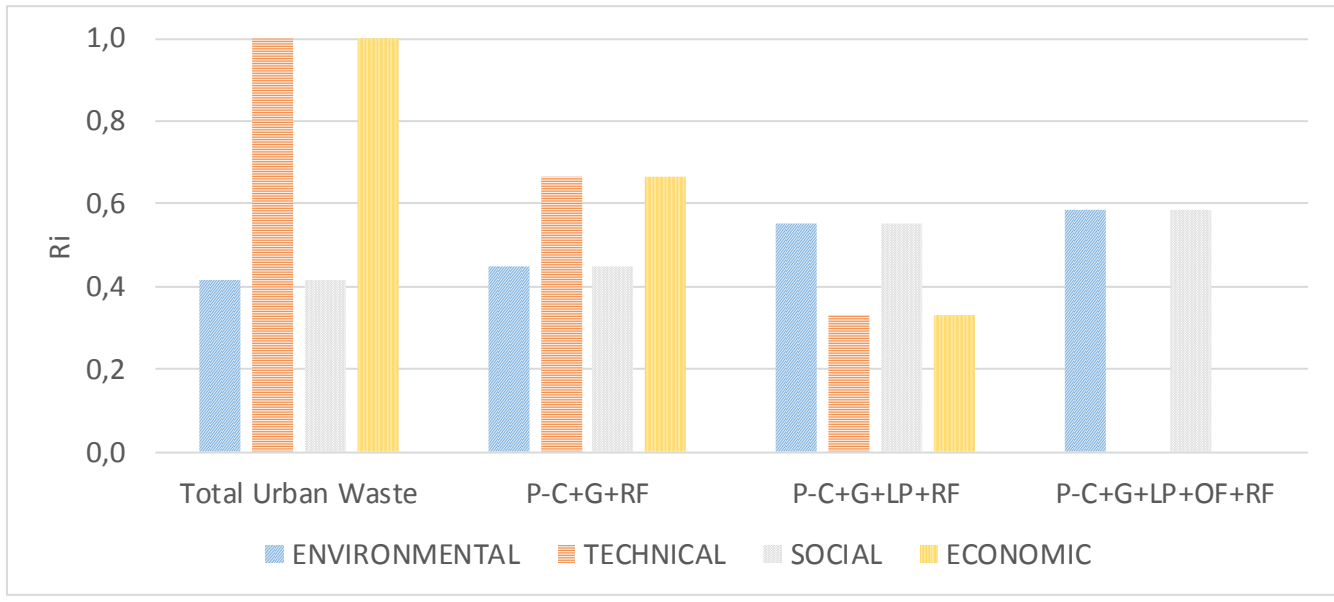

Fig. 2. Overall criteria rating of the separation model alternatives considered $\left(R_{k 11}\right)$.

\section{Collection systems}

To assess the different collection options considered, the indicators in Table 3 have been taken into account. This table shows the assessments of each alternative $\left(R_{g 2 i}\right)$.

"Odors" are predominant in containers situated on the sidewalk since large amounts of waste can remain in them for long periods of time. In addition, they are located very close to pedestrians, which makes the smell more easily noticeable. In the case of door-to-door collection, containers are smaller in size, geographically distributed in different areas, the amounts of waste are smaller, and they have a schedule for deposition, so they do not remain in the containers for a long time (Alvarez-Prado et al., 2010). Pneumatic collection systems reduce the level of odors considerably, thereby improving the hygiene conditions of the area (Punkkinen et al., 2012).

"Separation quality" will be lower in the underground and pneumatic containers (MAGRAMA, 2013a) because the mouths are small, which sometimes makes it difficult to introduce the waste and to distinguish the fractions corresponding to each container.

"Facilities" are more complex in the pneumatic collection system, since it is necessary to install a complex system of suction pipes (Teerioja et al., 2012). They are also relevant in the underground container system, where civil works are necessary to bury the containers. "Flexibility" is also associated with the infrastructures, as the less complex they are, the greater the flexibility of the system will be, since it will be possible to modify the situation, the size or the number of containers (Fundación para la Economía Circular, 2014). "Damage" will be more frequent in containers on the sidewalk, since their entire surface is exposed to the effects of the weather or vandalism.

"Complexity of implementation" is greater in pneumatic collection (Teerioja et al., 2012) and underground containers, due to the major civil works that need to be carried out. They are followed by door-to-door collection, since no large infrastructures are required for the planning of schedules and collection routes.

"Social involvement" is greater in systems with door-to-door collection, since users are more closely linked to the management of their waste and this increases their awareness (Alvarez-Prado et al., 2010).

"Service cost" data (MAGRAMA, 2013a) include cleaning, amortization, replacement and maintenance of containers, expenses and maintenance of vehicles, and staff costs. 
Table 3 Assessment of collection system alternatives.

\begin{tabular}{|c|c|c|c|c|c|c|}
\hline Stage & Criteria & Indicators & $\mathrm{KB}^{\mathrm{a}}$ & UB & PC & DDC \\
\hline \multirow{15}{*}{ 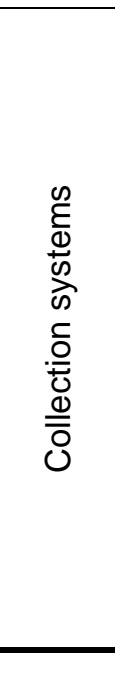 } & \multirow{4}{*}{ Environmental } & Odors & 4 & 3 & 1 & 1 \\
\hline & & Occupancy of public space & 4 & 3 & 3 & 1 \\
\hline & & Separation quality & 2 & 3 & 3 & 1 \\
\hline & & Greenhouse gas emissions & 1 & 3 & 4 & 4 \\
\hline & \multirow{4}{*}{ Technical } & Facilities & 2 & 3 & 4 & 1 \\
\hline & & Flexibility & 2 & 3 & 4 & 1 \\
\hline & & Damage & 4 & 3 & 3 & 2 \\
\hline & & Complexity of implementation & 1 & 3 & 4 & 3 \\
\hline & \multirow{4}{*}{ Social } & Convenience to the users & 1 & 3 & 3 & 4 \\
\hline & & Social involvement & 2 & 3 & 3 & 1 \\
\hline & & Job creation & 2 & 3 & 4 & 1 \\
\hline & & Distance from the home & 3 & 4 & 4 & 1 \\
\hline & \multirow{3}{*}{ Economic } & Facilities costs & 2 & 3 & 4 & 1 \\
\hline & & Service cost $(€ / t)$ & 130 & 105 & 160 & 150 \\
\hline & & & 0.56 & 0.39 & 0.20 & 0.62 \\
\hline
\end{tabular}

${ }^{2}$ KB, Kerbside Bins; UB, Underground Bins; PC, Pneumatic Collection; DDC, Door-to-Door Collection.

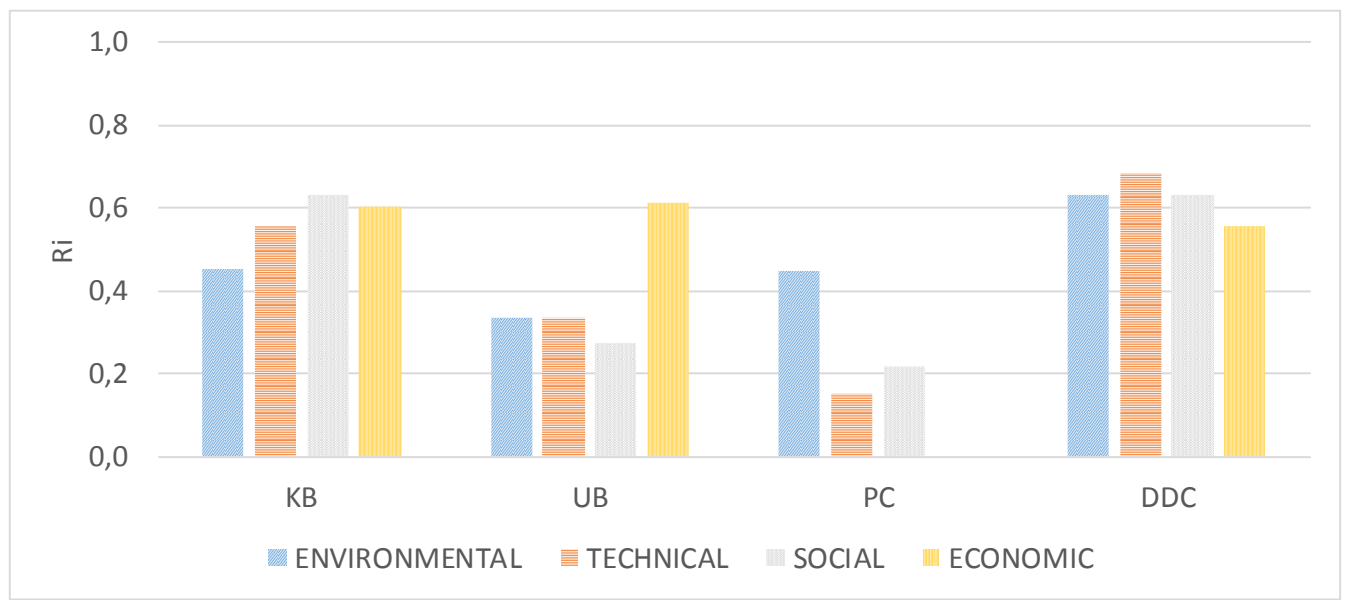

Fig. 3. Overall criteria for assessment of collection system alternatives considered $\left(\mathrm{R}_{\mathrm{kzi}}\right)$.

\section{Pre-treatments}

The pre-treatments considered in this study are shown in Table 4. This same table also shows the results of the assessment of each indicator for each type of pre-treatment $\left(R_{g 3 i}\right)$.

"Greenhouse gas emissions" are higher as more machinery is needed to carry out the process. Moreover, in the drying and pelletizing process the emissions increase due to the greater energy consumption.

As for "Water pollution", the pulping process with pre-hydrolysis is the one that consumes the most water and will therefore cause greater contamination of it, which will require a subsequent treatment. In the case of precomposting, leachate will be produced from the degradation of waste that will also need to be treated to avoid contamination of the adjacent waters. 
Regarding "Improvement of efficiency", with pre-hydrolysis pulping and with biological pre-treatment, better performances are obtained in the subsequent treatments. Both "Technological Complexity" and "Sensitivity of the process" are greater in the alternative of pulping with pre-hydrolysis since it requires greater monitoring of the control parameters to ensure its correct operation, as well as a more advanced process technology (teCH4+, 2018). "Occupational risks" are higher in those treatments in which workers are exposed to a greater number of dangerous situations, such as the use of machinery or direct contact with waste.

The comparison between the pre-treatment options should be made distinguishing between P1, P2 and P3. P1 - S, P2 - MGF and P3 - P are the best options within each pre-treatment stage (Table 4).

Table 4 Assessment of pre-treatment alternatives.

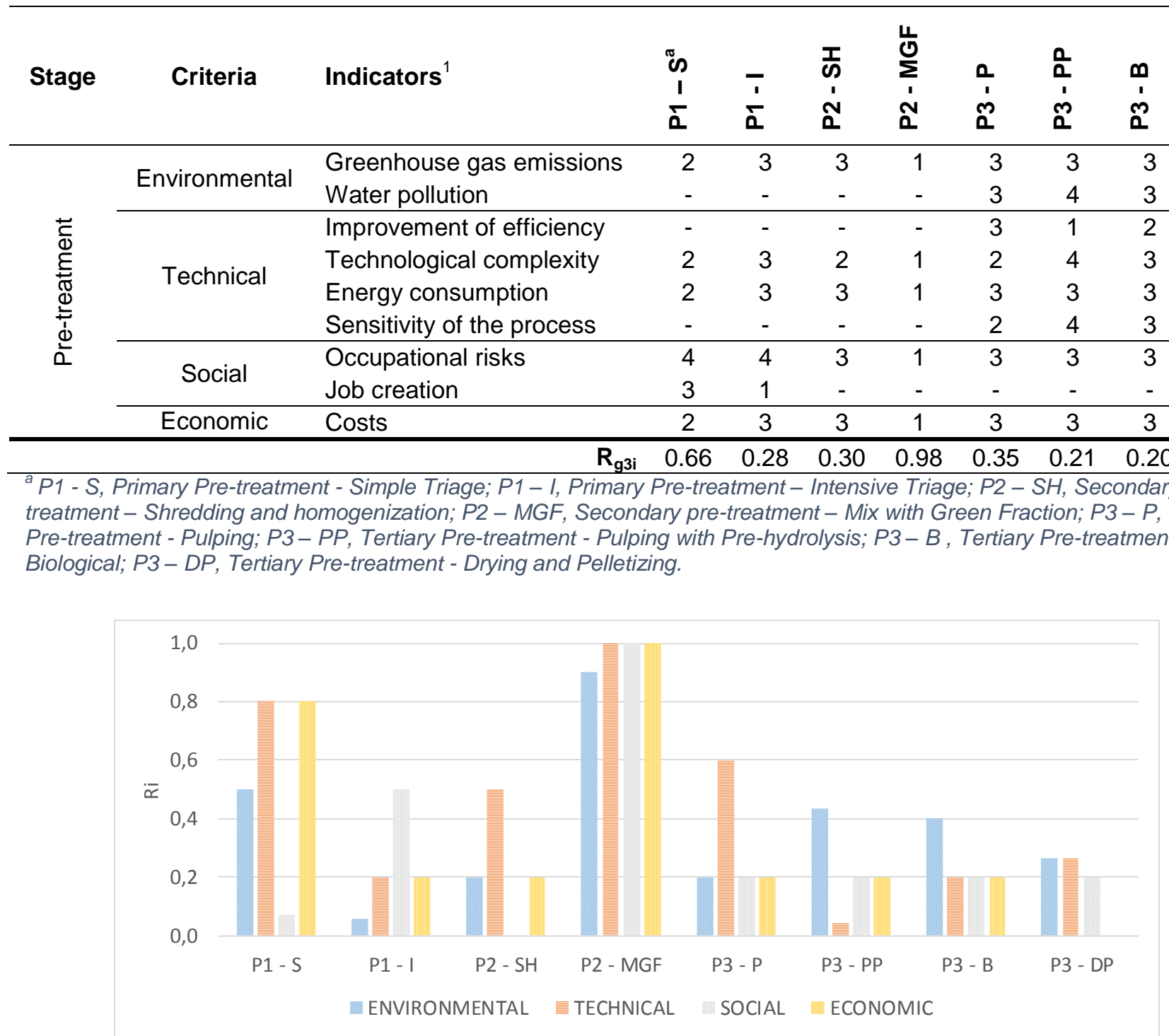

Fig. 4. Overall criteria for assessments of pre-treatment alternatives considered $\left(R_{k 3 i}\right)$.

\section{Treatments}

"Green House Gas emissions" have been assessed as net $\mathrm{CO}_{2}$ emissions, which correspond to those emitted in the process, except the ones potentially avoidable with the use of the products obtained. Of all the alternatives contemplated, the ones that can prevent the most emissions are those involving anaerobic digestion, while the most problematic treatment in terms of emissions would be the landfill deposit without biogas use.

\footnotetext{
${ }^{1}$ The symbol (-) indicates that the alternative has not been evaluated based on this criterion.
} 
Table 5 Assessment of treatment alternatives.

\begin{tabular}{|c|c|c|c|c|c|c|c|c|c|c|c|c|}
\hline Stage & Criteria & Indicators & $c^{a}$ & BAT & vc & DAS & WAD & $\mathbf{I}$ & G & $\mathbf{P}$ & $\mathbf{L}$ & LB \\
\hline \multirow{14}{*}{ 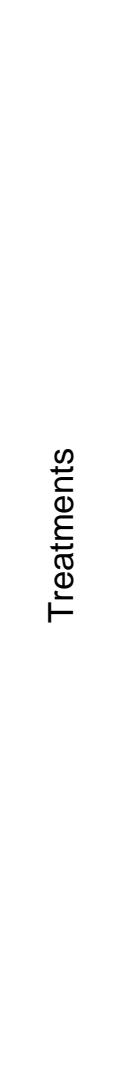 } & \multirow{4}{*}{ 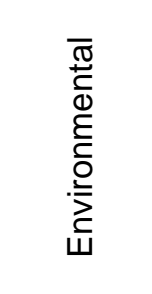 } & Greenhouse gas emissions ( $\mathrm{kg} \mathrm{CO}_{2}$-eq/t) [1] [2] [3] & -42 & -15 & -38 & -126 & -126 & -66 & -71 & -71 & 673.5 & 39.5 \\
\hline & & Soil occupation $\left(\mathrm{m}^{2} / \mathrm{t}\right)[4][5][6][7]$ & 0.8 & 0.8 & 7.63 & 1.29 & 1.29 & 0.1 & 0.1 & 0.1 & 3.22 & 3.22 \\
\hline & & Materials recovery (\% weight) [8] & 45 & 45 & 45 & 50 & 50 & 20 & 40 & 40 & 0 & 0 \\
\hline & & Odors & 3 & 3 & 3 & 3 & 3 & 1 & 1 & 2 & 5 & 4 \\
\hline & \multirow{4}{*}{ 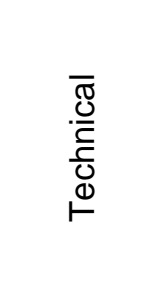 } & Energy produced (kwh/t) [8] & 0 & 0 & 0 & 889 & 889 & 750 & 555 & 555 & 0 & 55 \\
\hline & & Technological complexity & 2 & 2 & 2 & 3 & 4 & 4 & 4 & 5 & 2 & 3 \\
\hline & & Sensitivity of the process & 4 & 4 & 5 & 5 & 5 & 3 & 3 & 4 & 1 & 2 \\
\hline & & Energy consumption (kwh/t) [9] & 19 & 19 & 19 & 72 & 72 & 152 & 152 & 152 & 2 & 2,15 \\
\hline & \multirow{3}{*}{$\begin{array}{l}\overline{\bar{\sigma}} \\
\bar{\delta} \\
\infty\end{array}$} & Social Acceptance & 2 & 2 & 1 & 1 & 1 & 5 & 4 & 3 & 5 & 4 \\
\hline & & Occupational risks [10] & 4 & 4 & 3 & 2 & 2 & 4 & 4 & 4 & 5 & 4 \\
\hline & & Job creation (Job/1000t) [11] [6] & 0.4 & 0.4 & 0.5 & 0.33 & 0.1 & 0.1 & 0.1 & 0.1 & 0.1 & 0.1 \\
\hline & \multirow{3}{*}{ 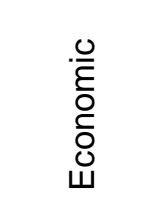 } & Investment costs (€/t-cap) [12] & 185 & 185 & $-\mathrm{b}$ & 487 & 205 & 472 & 575 & 575 & 77.78 & 104.4 \\
\hline & & Service costs $(€ /$ t/year) [12] & 5.6 & 5.6 & $-\mathrm{b}$ & 6 & 6 & 33.8 & 17.3 & 17.3 & 13.6 & 14.5 \\
\hline & & Economic remunerations $(€ / t)[13]$ & 1.65 & 1.65 & $-\mathrm{b}$ & 11.13 & 11.13 & 32.64 & 25.68 & 25.68 & 0 & 3.97 \\
\hline & & $\mathbf{R}_{\mathbf{g} 4 \mathrm{i}}$ & 0.61 & 0.61 & 0.44 & 0.67 & 0.66 & 0.43 & 0.50 & 0.52 & 0.33 & 0.42 \\
\hline
\end{tabular}

[1] (AEA, 2011); [2] (Chan et al., 2011); [3] (Smith et al., 2001)

[4] (Huerta et al., 2008); [5] (BINAS, 2014); [6] (COGERSA, 2014); [7] (G-advisory, 2015)

[8] (MMA, 2005); [9] (Hong et al., 2010); [10] (Barberá, 2011)

[11] (Friends of the Earth, 2010); [12] (Crowe et al., 2002); [13] (Milutinović et al., 2014)

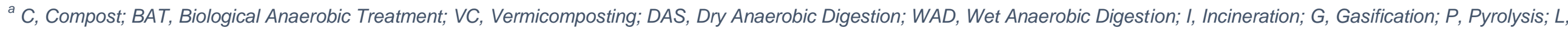
Landfill without biogas use; LB, Landfill with biogas use. ${ }^{b}$ No information was found for this indicator. 
Regarding the "Sensitivity of the process", those that have biological processes for which a greater follow-up of the established control parameters is needed have been considered as the most sensitive treatments. "Social acceptance" attempts to represent the alternatives that are perceived in a more positive way by the surrounding populations. Thus, due to their low rates of emissions, noise and pollution, treatments such as vermicomposting or anaerobic digestion are better accepted socially than others such as incineration (Barberá, 2011).

On the other hand, the jobs generated by each thousand tons treated, "Job creation", will be higher in less mechanized treatments and in ones which treat smaller amounts of waste such as vermicomposting or traditional composting. The "Investment Costs" include the costs of the land, planning, construction and initial operation of each installation. "Costs of operation" include all expenses related to the operation and maintenance of the facilities except those related to the management of waste and personnel.

In spite of having low ratings in the technical criteria due to their high complexity, DAD and WAD are the best rated alternatives in the overall calculation (Table 5).

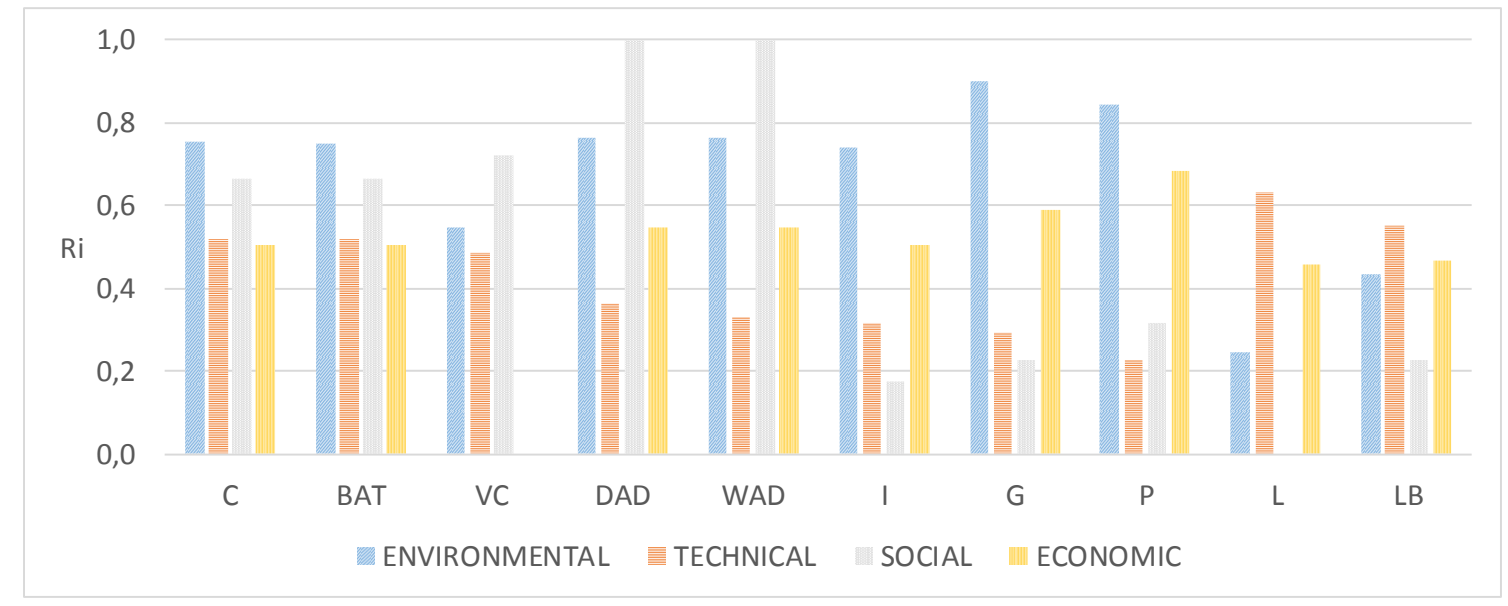

Fig. 5. Overall criteria for assessment of treatment alternatives considered $\left(R_{k 4 i}\right)$.

\section{Applications}

"Improvement in soil conditions" considers the capacity of the products obtained in the treatment processes to increase the quality of the soils in which they are applied. These improvements include resistance to erosion, greater water retention, and nutrient supply. This is the case of the use of compost, which provides numerous benefits to the soils in which it is applied (Huerta et al., 2008). The capacity of these applications to prevent other possible emissions or sources of pollution, "Emissions avoided", has also been considered. One example is the generation of energy, which avoids the need for its generation with other types of non-renewable sources. In the indicator "Required quality", the rating has been established according to the importance of the existence of improper materials (considering as improper any material not belonging to the organic fraction of urban waste), very high quality being necessary for applications of use in soil (Gobierno de España, 2013) (agriculture, gardening, recovery of degraded soil, etc.) and lower in other types of applications such as energy generation. The "Involvement of users" is higher in applications with which the population is in direct contact, as is the case of land application techniques.

Finally, the economic criteria will be more favorable in those applications that have a better quality (compost), are of essential use for the population, or can be used in the treatment plant itself (energy). 
Table 6 Assessment of application alternatives.

\begin{tabular}{|c|c|c|c|c|c|c|}
\hline Stage & Criteria & Indicators & $\mathrm{CAS}^{\mathrm{a}}$ & BAS & EG & D \\
\hline \multirow{6}{*}{$\begin{array}{l}\frac{.}{.0} \\
\frac{0}{\pi} \\
\frac{.0}{0} \\
\frac{0}{2}\end{array}$} & \multirow{2}{*}{ Environmental } & Improvement in soil conditions & 1 & 3 & 3 & 4 \\
\hline & & Emissions avoided & 2 & 3 & 1 & 4 \\
\hline & Technical & Required quality & 4 & 3 & 2 & 2 \\
\hline & Social & Involvement of users & 1 & 2 & 3 & 4 \\
\hline & \multirow{2}{*}{ Economic } & Demand & 1 & 2 & 1 & 4 \\
\hline & & Remunerations & 1 & 2 & 1 & 4 \\
\hline & & & 0.64 & 0.51 & 0.69 & 0.17 \\
\hline
\end{tabular}

${ }^{a}$ CAS, Compost Application in Soil; BAS, Biostabilized Application in Soil; EG, Energy Generation; D, Disposal.

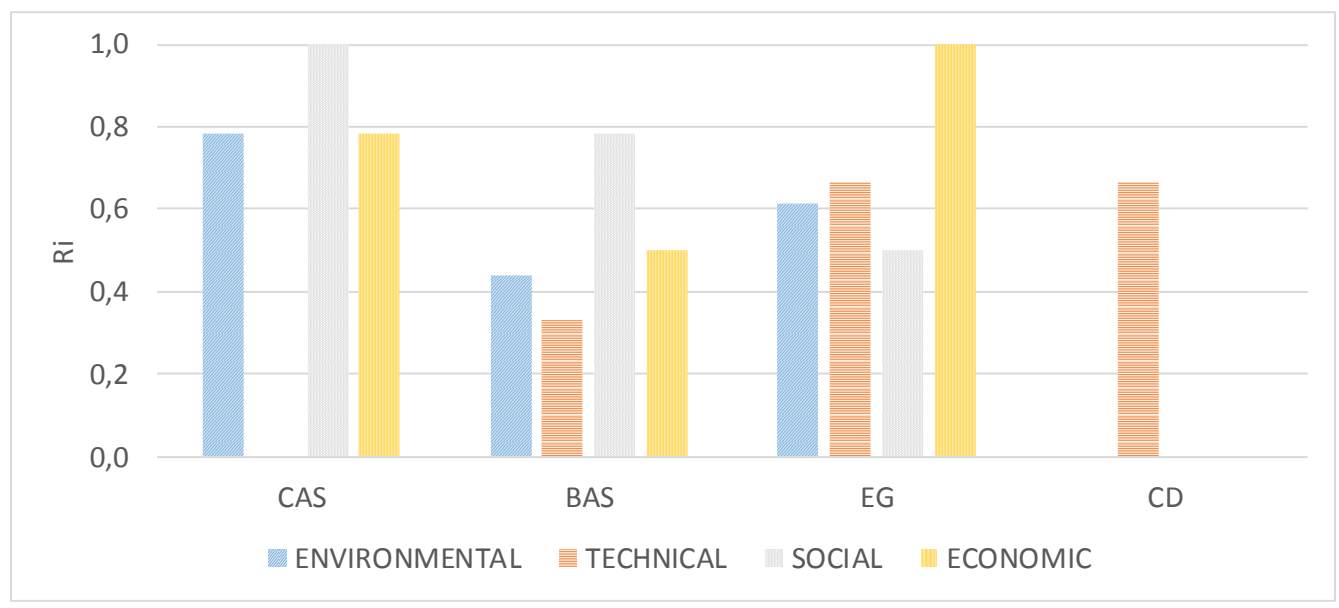

Fig. 6. Overall criteria for assessment of application alternatives considered $\left(R_{k 5 i}\right)$.

\section{Computer application "DELIGES"}

In order to integrate and facilitate the application of the compatibility criteria and evaluations of the proposed indicators, the computer application "DELIGES" was created. It is a Windows desktop application built on Microsoft .Net Framework 4.0., and programmed in C\# language with the Visual Studio 2017 environment. It is an MDI (Multi Document Interface) application based on Windows Forms that also uses some Infragistics controls. As a data repository, it uses local plain text files in XML format.

The application includes ratings for the alternatives and the compatibility between them, which coincide with the ones described earlier in this document. These assessments may be modified according to the interests of users and the scenarios studied. The application starts by selecting alternatives that are already implemented in the current management system and cannot be modified, or those that have been planned for some reason. The application hides the alternatives of each stage that are not compatible with the selected ones so that when marking alternatives, only those that are compatible will remain. Only one option can be chosen within each stage, except in "Pre-treatments" and "Applications", where several alternatives can be selected simultaneously. Once all the stages have been defined, the management line will finally be assessed based on the weighted average of the environmental, technical, economic, social and compatibility assessments of each alternative.

Through a control panel, the weightings given to each of the criteria can be modified. In this way, if the user is interested in selecting a management line that favors and protects the environment, the weighting of the environmental criteria will be increased, which will affect the final score of the chosen system. Likewise, the weights of each of the stages can also be modified according to the needs of each user, although, by default, the criteria and stages are weighted equally in the application. Once the management system has been created, it can be saved on a separate tab, and several management options can thus be stored to be compared later. 


\section{Case study}

The proposed case study was carried out in the region of Cantabria, Spain, and the municipal solid waste management system of this region begins with a separate collection in four fractions ( $P-C+G+L P+M W)$. Although a number of different collection systems are used, in Cantabria containers on sidewalks prevail. There are also small areas fitted with pneumatic collection and underground containers, located mostly in the capital, Santander.

Mixed waste collected in the entire region is transported to Meruelo's Integral Waste Treatment Plant, where a biological mechanical treatment is carried out. The plant has two treatment lines, one initially devoted to the separation of the LP fraction, and another for mixed waste. The first is not currently used. The second begins with an intensive manual triage, through which P-C, LP and G are separated from mixed waste, which includes the organic fraction. Once separated, the fraction smaller than $60 \mathrm{~mm}$ is subjected to an aerobic biological treatment, the result being a biostabilized product, after a subsequent refining process.

In the past, the biostabilized product was marketed for use as a soil conditioner. However, the current soil regulations (Gobierno de España, 2013) underline the differences between compost and biostabilized material. Specific regulations (MAGRAMA, 2013b) limit the use of biostabilized materials obtained from the organic fraction that is not separated at source, with restrictions similar to Class $C$ Compost, that is, they cannot be used in doses exceeding five tons of dry matter per hectare per year. These restrictions significantly reduce the value of the biostabilized product, and hinder its sale. This is the case of Cantabria, where, for several months, the biostabilized product obtained does not have any type of use and is poured directly into the landfill.

Given this situation, changes in the collection scheme have been proposed, such as incorporating the separate collection of the organic fraction.

To minimize the cost of this change, it is suggested to maintain the type of collection and continue using the current plant, taking advantage of the two lines, one for the organic fraction and the other for the mixed fraction. This installation will be gradually modified until the separate collection of the organic fraction has been implemented throughout the region and reaches an adequate level of efficiency.

For the separated organic fraction line, a simple triage has been planned, since, because the number of improper materials present must be lower than in the mixed waste, there will be less need for separation. Next, the organic matter will be mixed with green fraction collected in the same area. This will make it possible to take advantage of this fraction and improve the conditions for composting, which will be carried out as the main process. This treatment will require only minor modifications to the current facilities.

Finally, the material obtained in this process, compost, will have characteristics that make it suitable for use in any type of soil, thus maintaining and even improving on the conditions of sale and demand of the biostabilized product in previous years, until its use was restricted. In addition, this product will provide benefits to soils, such as enhancement of carbon sequestration, greater water retention or improvement of the structure (EPA, 2018).

Figure 7 shows the evolution of the municipal waste management system described and the results of the overall evaluation of each of them conducted with the DELIGES tool, according to the assessment and weighting described in the previous section. The results show that, overall, the planned alternative improves current and past scenarios ( $28 \%$ and $20 \%$ respectively according to the scores obtained).

It is noteworthy that the best rating is far from the theoretical maximum for the set of indicators applied, some of which are in opposition. The technical indicators for the treatments, for instance the technological complexity (evaluated negatively), increase as the energy production of the process increases. In other scenarios, other indicators could be chosen, depending on the indicators to be assessed, and this circumstance would change. 


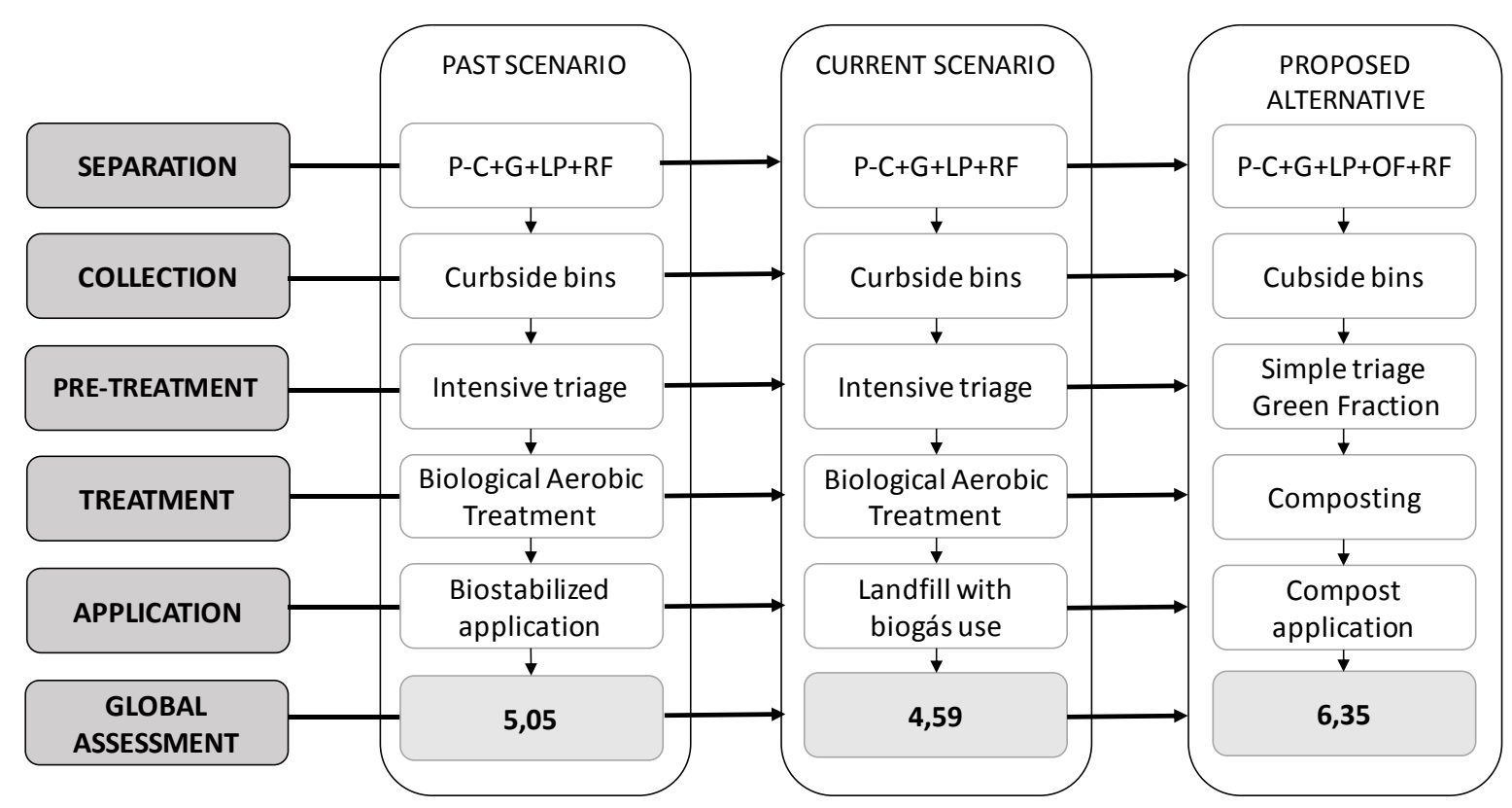

Fig. 7. Evolution of the municipal solid waste management system studied.

Figure 8 allows the results to be analyzed in detail. It shows how the limitations in the use of the biostabilized product decreased the score of the system in all the criteria except the technical one. Even though the management line does not change, its rating is significantly reduced. The rating of the compatibility criterion decreases due to the change in the final use of the products obtained, which does not take advantage of the complex treatment line. However, disposing of the waste in landfill has lower quality requirements than other final applications, which explains why the technical assessment increases with respect to the past scenario.

The implementation of the proposed alternative considerably improves all aspects except the technical one. The rating is lower in this criterion as a result of a more complex separation and collection due to the inclusion of the source-segregated organic fraction and stringent requirements as regards product quality.

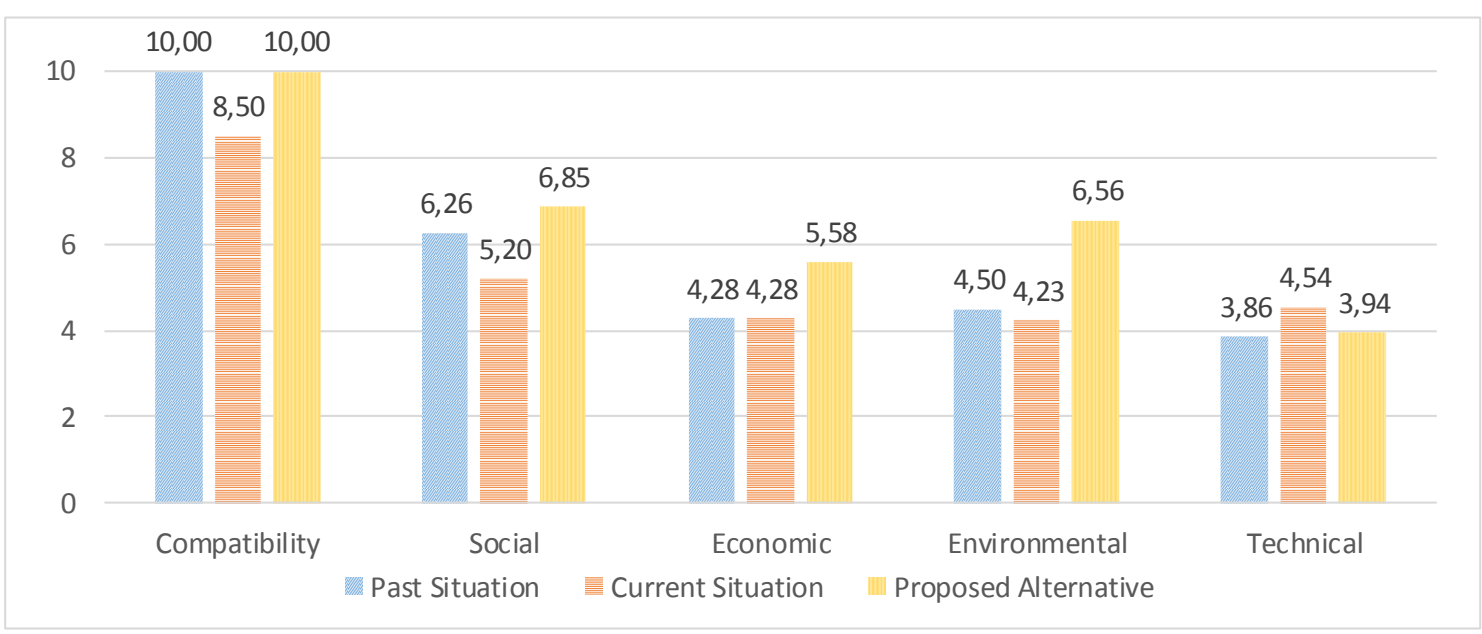

Fig.8. Rating obtained in each scenario of the proposed alternative with respect to the current and past scenario.

The compatibility becomes optimal, because the use of waste justifies each of the elements included in the management line.

Although collection costs will be higher as a fraction is added to the current scheme, the lower need for pretreatment, together with the new sale conditions of the product obtained in the process, make the global economic evaluation positive in relation to the initial one. 
Furthermore, the environmental criterion improves considerably due to several factors. First, the source segregation of the organic fraction favors its use, thereby avoiding the emissions that this type of waste would generate if deposited in a landfill. On the other hand, with lower concentrations of improper materials in the organic matter collected, a final product is obtained with physical-chemical characteristics that allow its use in soils without jeopardizing the environment.

Finally, although the system requires greater efforts from citizens, they will be more involved in proper management, which can lead to greater social awareness. In addition, aspects such as occupational risks and job creation will be favored with the proposed solution (Friends of the Earth, 2010).

\section{Conclusions}

A tool capable of evaluating, comparing and classifying waste management lines according to different criteria has been developed. The tool is useful for users with different interests. Specific training in waste management is not essential for its use, since it gathers essential default information so that the user is able to assess several available options. Furthermore, users with more experience in the sector can modify and adapt the tool to the needs of each particular situation. It can be enriched by introducing new criteria and other alternatives, even specific technologies within the general ones included in this work. Its flexibility, resulting from the possibility of weighting the different stages and criteria, makes it possible to cover diverse cases.

The multicriteria analysis method and the assessments of each of the proposed alternatives have led to a series of conclusions that serve as an example for the selection of biowaste management lines. In the event that these assessments or the alternatives themselves vary, the results obtained could be altered.

In the separation stage, the ratings of all the criteria are directly proportional to the number of separate fractions. Regarding the collection systems among the options considered in this work, the best rated is the door-to-door system. Despite having high transport emissions, it has positive environmental implications, such as a better quality of the separated fraction or lower occupation of public space, which place it at the head, followed by kerbside bin collection.

Of the treatments assessed, the two types of anaerobic digestion (dry and wet) obtain the best ratings, due to their low greenhouse gas emissions, high energy production and good social acceptance, despite presenting high technical complexity. The thermal treatments are the worst rated in this stage, due to their low social acceptance in the area considered, in addition to the high associated costs and their technical complexity. Finally, within the options of final application, both the use of compost in soil and the generation of energy have the best ratings, due to the fact that they allow the use of waste and prevent environmental pollution.

\section{Acknowledgements}

This research was financially supported by the University of Cantabria, the Society for the regional Development of Cantabria (SODERCAN) and the FEDER Operational Programme for Cantabria.

\section{References}

Abdullahi, Y.A., Akunna, J.C., White, N.A., Hallett, P.D., Wheatley, R., 2008. Investigating the effects of anaerobic and aerobic post-treatment on quality and stability of organic fraction of municipal solid waste as soil amendment. Bioresour. Technol. 99, 8631-8636. https://doi.org/10.1016/j.biortech.2008.04.027

AEA - The Agricultural Engineers Association, 2011. DECC's GHG Conversion Factors for Company Reporting. Department of Energy and Climate Change (DECC) y Department for Environment, Food and Rural Affairs (Defra), London, United Kingdom.

Alvarez-Prado, L., Aymemí-González, A., Codina-Pujols, E., Coll-Gelabert, E., Colomer-Missé, J., Gijón-López, R., Llopart-Grácia, S., Martín-Gascón, P., Puig-Ventosa, I., Salvans-Clusellas, C., 2010. Manual de recogida selectiva puerta a puerta. Agencia de Residuos de Cataluña, Barcelona, España. 
Barberá, L., 2011. Biometanización en plantas industriales avanzadas. Generación de energía a partir de residuos sólidos urbanos. Madrid, España.

BINAS - Banco de Ideas de Negocios Ambientales Sostenibles, 2014. Vermicompostaje de residuos orgánicos. Tenerife, España.

Capson-Tojo, G., Trably, E., Rouez, M., Crest, M., Steyer, J.-P., Delgenès, J.-P., Escudié, R., 2017. Dry anaerobic digestion of food waste and cardboard at different substrate loads, solid contents and codigestion proportions. Bioresour. Technol. 233, 166-175. https://doi.org/10.1016/j.biortech.2017.02.126

Chan, Y.C., Sinha, R.K., Weijin Wang, 2011. Emission of greenhouse gases from home aerobic composting, anaerobic digestion and vermicomposting of household wastes in Brisbane (Australia). Waste Manag. Res. 29, 540-548. https://doi.org/10.1177/0734242X10375587

COGERSA - Consorcio para la Gestión de Residuos en Asturias, 2014. Planta de biometanización de fracción orgánica selectiva y lodos de depuradora de Cogersa en Asturias. FuturENVIRO Marzo 2014, 37-49.

Crowe, M., Nolan, K., Collins, C., Carty, G., Donlon, B., Kristoffersen, M., 2002. Biodegradable municipal waste management in Europe. Part 3: Technology and market issues.European Environment Agency. Copenhagen, Denmark.

De Feo, G., Ferrara, C., Finelli, A., Grosso, A., 2019. Environmental and economic benefits of the recovery of materials in a municipal solid waste management system. Environ. Technol. (United Kingdom) 40, 903911. https://doi.org/10.1080/09593330.2017.1411395

Di Maria, F., Micale, C., 2015. Life cycle analysis of management options for organic waste collected in an urban area. Environ. Sci. Pollut. Res. 22, 248-263. https://doi.org/10.1007/s11356-014-3330-9

Edwards, J., Othman, M., Crossin, E., Burn, S., 2018. Life cycle assessment to compare the environmental impact of seven contemporary food waste management systems. Bioresour. Technol. 248, 156-173. https://doi.org/10.1016/j.biortech.2017.06.070

EPA (Environmental Protection Agency), 2018. Reducing the Impact of Wasted Food by Feeding the Soil and Composting [WWW Document]. URL https://www.epa.gov/reducefoodwaste/reducing-impact-wasted-foodfeeding-soil-and-composting\#benefits

European Parliament and Council, 2008. Directive 2008/98/EC of the European Parliament and of the Council of 19 November 2008 on waste and repealing certain directives. Off. J. Eur. Union 3-30. https://doi.org/2008/98/EC.; 32008L0098

Friends of the Earth, 2010. More jobs, less waste. Potential for job creation through higher rates of recycling in the UK and EU. London, United Kingdom.

Fundación para la Economía Circular, 2014. Estrategias para la gestión sostenible de los residuos en el horizonte 2020. Estudio de base 2: Informe estratégico sobre los biorresiduos. Madrid, España.

G-advisory, 2015. Estudio sobre los impactos socio-económicos y ambientales de la valorización energética de los residuos urbanos en España y Andorra. AEVERSU - Asociación de Empresas de Valorización Energética de RSU.

Gallardo, A., Prades, M., D., M., J., F., 2012. Separate Collection Systems for Urban Waste (UW), in: Management of Organic Waste. InTech, pp. 978-953-307-925-7. https://doi.org/10.5772/32508

Gobierno de España, 2013. Real Decreto 506/2013, de 28 de junio, sobre productos fertilizantes. Boletín Of. del Estado 164, 5119-51207. https://doi.org/10.1109/CDC.2008.4739052

Goulart Coelho, L.M., Lange, L.C., Coelho, H.M.G., 2017. Multi-criteria decision making to support waste management: A critical review of current practices and methods. Waste Manag. Res. 35, 3-28. https://doi.org/10.1177/0734242X16664024

Gupta, R., Garg, V.K., 2017. Vermitechnology for Organic Waste Recycling, in: Wong, J., Tyagi, R., Pandey, A. (Eds.), Current Developments in Biotechnology and Bioengineering: Solid Waste Management. Elsevier, pp. 83-112. https://doi.org/10.1016/B978-0-444-63664-5.00005-8

Hong, J., Li, X., Zhaojie, C., 2010. Life cycle assessment of four municipal solid waste management scenarios in China. Waste Manag. 30, 2362-2369. https://doi.org/10.1016/j.wasman.2010.03.038

Huerta, Ó., López, M., Soliva, M., Zaloña, M., 2008. Compostaje de residuos municipales. Control del proceso, rendimiento y calidad del producto. Escuela Superior de Agricultura de Barcelona, Barcelona, España.

Hwang, C., Yoon, K., 1981. Methods for Multiple Attribute Decision Making, Multiple Attribute Decision Making. Lecture Notes in Economics and Mathematical Systems. Berlin, Heidelberg, Germany. 
Kaza, S., Yao, L.C., Bhada-Tata, P., Van Woerden, F., 2018. What a Waste 2.0 : A Global Snapshot of Solid Waste Management to 2050. Urban Development. World Bank Group, Washington D.C., USA.

Li, C., Mörtelmaier, C., Winter, J., Gallert, C., 2014. Effect of moisture of municipal biowaste on start-up and efficiency of mesophilic and thermophilic dry anaerobic digestion. Bioresour. Technol. 168, 23-32. https://doi.org/10.1016/j.biortech.2014.02.118

Lombardi, L., Carnevale, E.A., Corti, A., 2015. Comparison of different biological treatment scenarios for the organic fraction of municipal solid waste. Int. J. Environ. Sci. Technol. 12, 1-14. https://doi.org/10.1007/s13762-013-0421-y

MAGRAMA, 2013a. Gestión de biorresiduos de competencia municipal - Guia para la implantación de la recogida separada y tratamiento de la fracción orgánica. Madrid, España.

MAGRAMA, 2013b. Decálogo para la utilización del material bioestabilizado y del compost no inscrito en el registro de productos fertilizantes mediante la operación R10. Madrid, España.

Maurer, M., Bufardi, A., Tilley, E., Zurbrügg, C., Truffer, B., 2012. A compatibility-based procedure designed to generate potential sanitation system alternatives. J. Environ. Manage. 104, 51-61. https://doi.org/10.1016/j.jenvman.2012.03.023

Milutinović, B., Stefanović, G., Dassisti, M., Marković, D., Vučković, G., 2014. Multi-criteria analysis as a tool for sustainability assessment of a waste management model. Energy 74, 190-201. https://doi.org/10.1016/j.energy.2014.05.056

MMA - Ministerio de Medio Ambiente, 2005. Gestión de residuos urbanos biodegradables en Europa. Informe temático. Madrid, España.

Ng, B.J.H., Mao, Y., Chen, C.L., Rajagopal, R., Wang, J.Y., 2017. Municipal food waste management in Singapore: practices, challenges and recommendations. J. Mater. Cycles Waste Manag. 19, 560-569. https://doi.org/10.1007/s10163-015-0405-8

Pubule, J., Blumberga, A., Romagnoli, F., Blumberga, D., 2015. Finding an optimal solution for biowaste management in the Baltic States. J. Clean. Prod. 88, 214-223. https://doi.org/10.1016/j.jclepro.2014.04.053

Punkkinen, H., Merta, E., Teerioja, N., Moliis, K., Kuvaja, E., 2012. Environmental sustainability comparison of a hypothetical pneumatic waste collection system and a door-to-door system. Waste Manag. 32, 1775-1781. https://doi.org/10.1016/j.wasman.2012.05.003

Santos, S.M., Silva, M.M., Melo, R.M., Gavazza, S., Florencio, L., Kato, M.T., 2017. Multi-criteria analysis for municipal solid waste management in a Brazilian metropolitan area. Environ. Monit. Assess. 189, 561. https://doi.org/10.1007/s10661-017-6283-x

Smith, A., Brown, K., Ogilvie, S., Rushton, K., Bates, J., 2001. Waste management options and climate change. Final report to the European Commission. Office for Official Publications of the European Communities, Luxembourg, Luxembourg.

teCH4+, 2018. Thermal Hydrolysis [WWW Document]. URL www.tech4plus.com (accessed 5.14.18).

Teerioja, N., Moliis, K., Kuvaja, E., Ollikainen, M., Punkkinen, H., Merta, E., 2012. Pneumatic vs. door-to-door waste collection systems in existing urban areas: A comparison of economic performance. Waste Manag. 32, 1782-1791. https://doi.org/10.1016/j.wasman.2012.05.027

Vea, E.B., Martinez-Sanchez, V., Thomsen, M., 2018. A review of waste management decision support tools and their ability to assess circular biowaste management systems. Sustain. 10, 40-60.

https://doi.org/10.3390/su10103720 
Table 1. Compatibility Matrix for the biowaste management alternatives defined in this work.

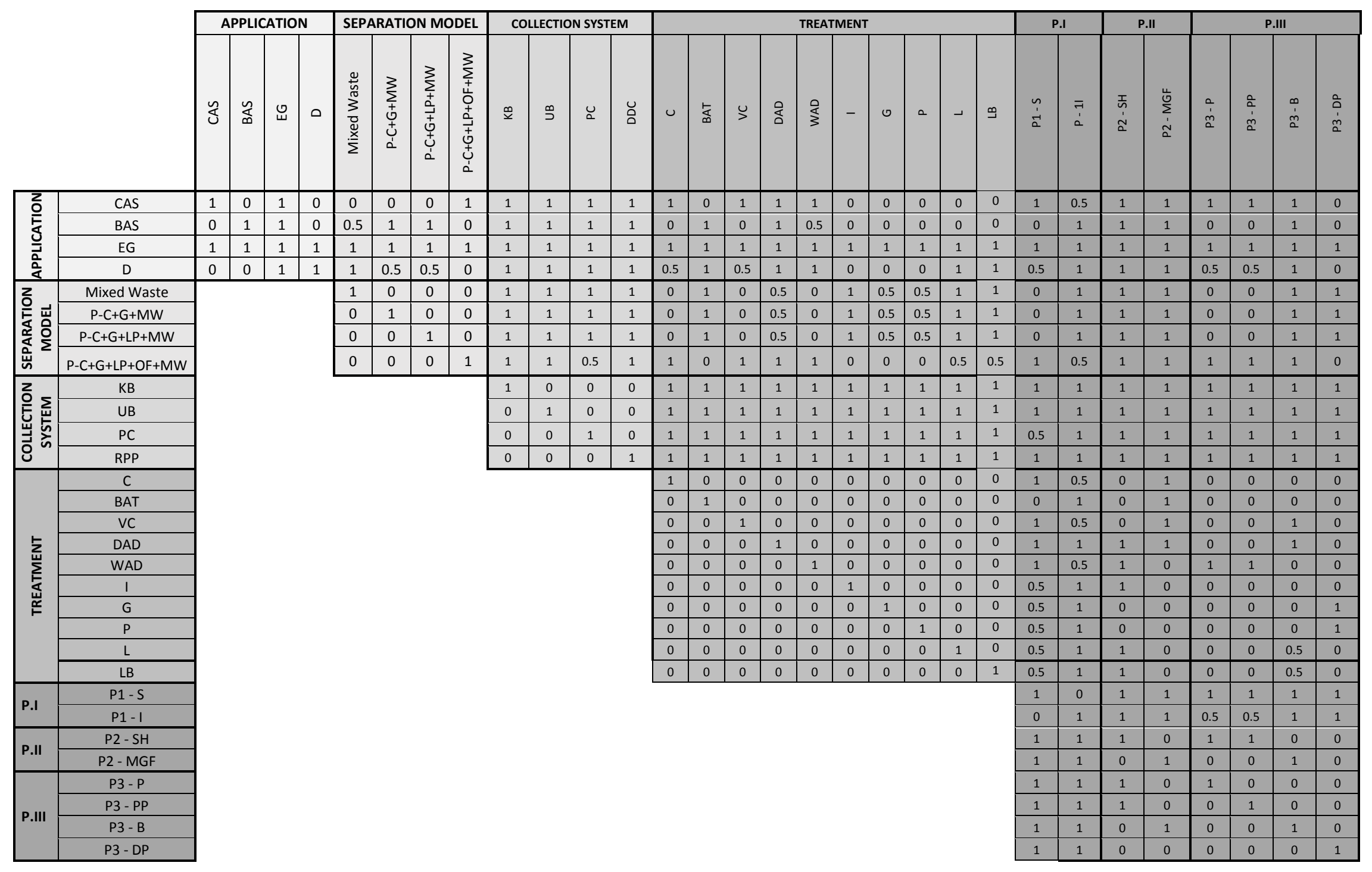


Table 2. Assessment of separation model alternatives.

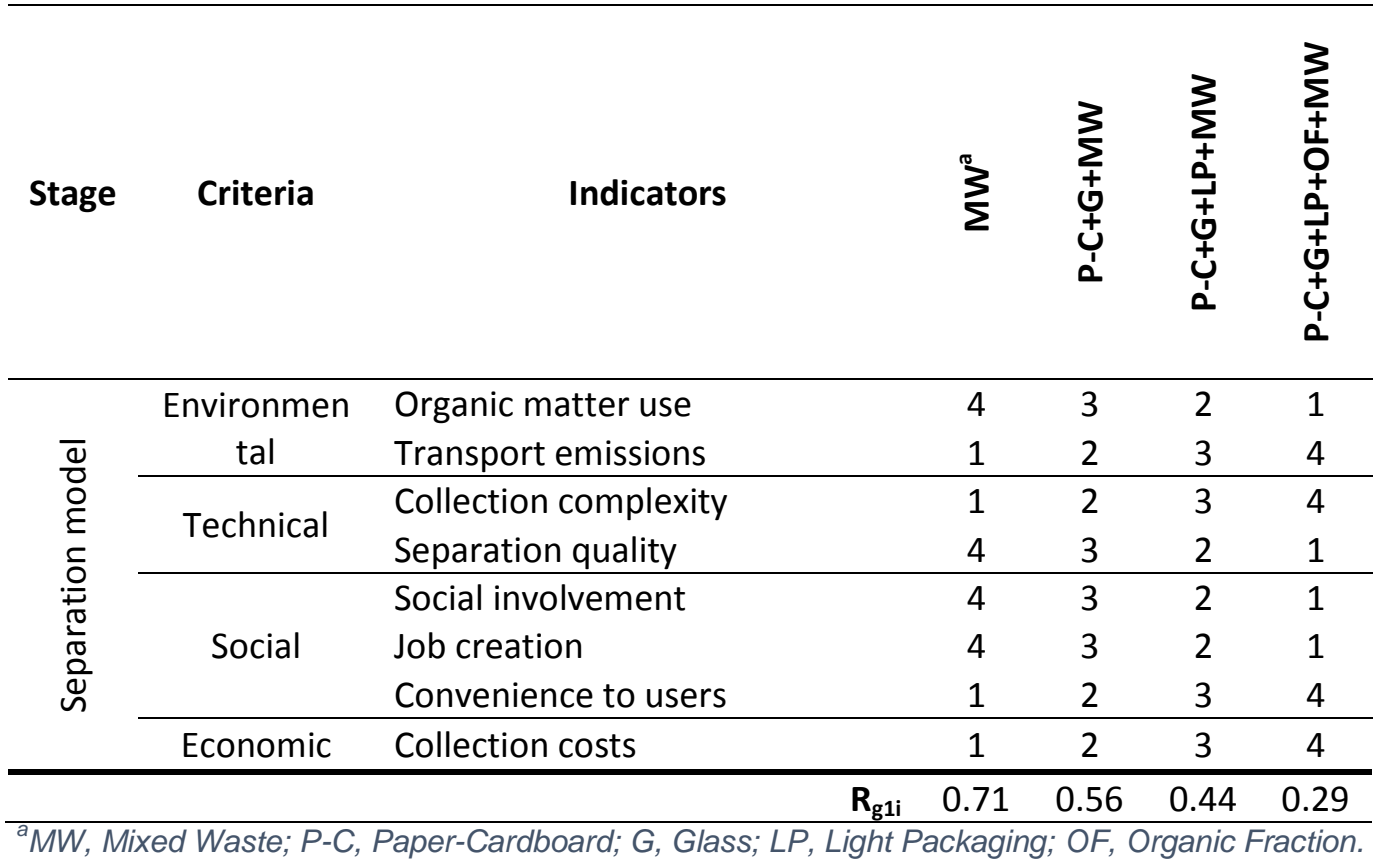

Table 3 Assessment of collection system alternatives.

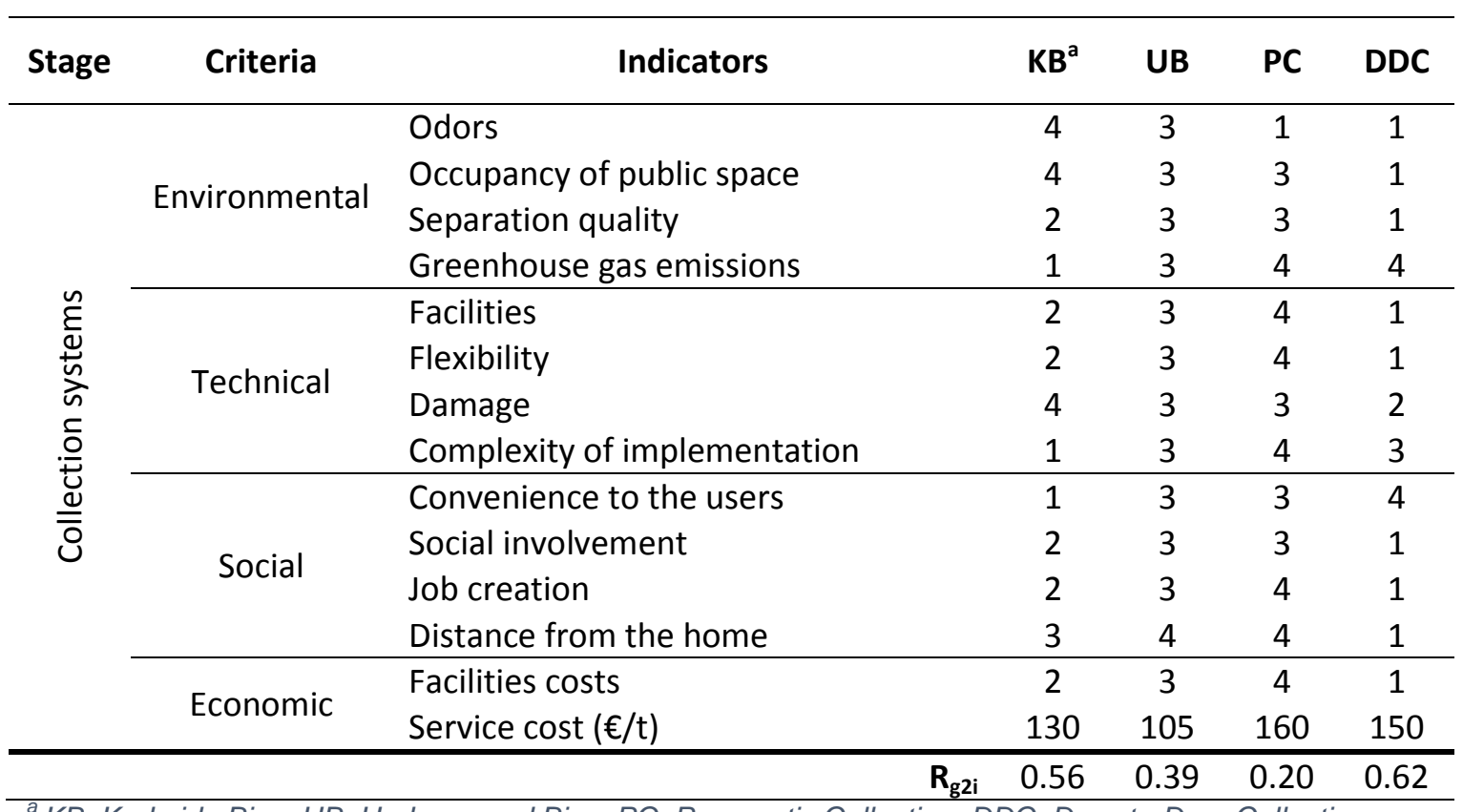

${ }^{a}$ KB, Kerbside Bins; UB, Underground Bins; PC, Pneumatic Collection; DDC, Door-to-Door Collection. 
Table 4 Assessment of pre-treatment alternatives.

\begin{tabular}{|c|c|c|c|c|c|c|c|c|c|c|}
\hline Stage & Criteria & Indicators $^{1}$ & $\begin{array}{c}n \\
1 \\
\frac{1}{0}\end{array}$ & $\frac{-}{a}$ & $\begin{array}{l}\frac{1}{n} \\
\vdots \\
\Sigma\end{array}$ & 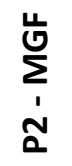 & $\begin{array}{l}n \\
n \\
a\end{array}$ & $\begin{array}{l}\frac{0}{a} \\
\dot{m} \\
a\end{array}$ & $\begin{array}{l}m \\
n \\
n\end{array}$ & $\begin{array}{l}0 \\
0 \\
\dot{m}\end{array}$ \\
\hline \multirow{9}{*}{ 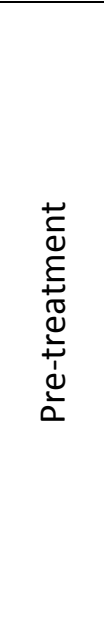 } & \multirow{2}{*}{$\begin{array}{l}\text { Environmen } \\
\text { tal }\end{array}$} & $\begin{array}{l}\text { Greenhouse gas } \\
\text { emissions }\end{array}$ & 2 & 3 & 3 & 1 & 3 & 3 & 3 & 4 \\
\hline & & Water pollution & - & - & - & - & 3 & 4 & 3 & 2 \\
\hline & \multirow{4}{*}{ Technical } & $\begin{array}{l}\text { Improvement of } \\
\text { efficiency }\end{array}$ & - & - & - & - & 3 & 1 & 2 & 3 \\
\hline & & $\begin{array}{l}\text { Technological } \\
\text { complexity }\end{array}$ & 2 & 3 & 2 & 1 & 2 & 4 & 3 & 3 \\
\hline & & Energy consumption & 2 & 3 & 3 & 1 & 3 & 3 & 3 & 4 \\
\hline & & $\begin{array}{l}\text { Sensitivity of the } \\
\text { process }\end{array}$ & - & - & - & - & 2 & 4 & 3 & 2 \\
\hline & \multirow{2}{*}{ Social } & Occupational risks & 4 & 4 & 3 & 1 & 3 & 3 & 3 & 3 \\
\hline & & Job creation & 3 & 1 & - & - & - & - & - & - \\
\hline & \multirow[t]{3}{*}{ Economic } & Costs & 2 & 3 & 3 & 1 & 3 & 3 & 3 & 4 \\
\hline \multirow{2}{*}{\multicolumn{2}{|c|}{$\mathbf{R}_{\mathrm{g} 3 \mathrm{i}}$}} & & 0.6 & 0.2 & 0.3 & 0.9 & 0.3 & 0.2 & 0.2 & 0.3 \\
\hline & & & 6 & 8 & 0 & 8 & 5 & 1 & 0 & 2 \\
\hline
\end{tabular}

\footnotetext{
${ }^{1}$ The symbol (-) indicates that the alternative has not been evaluated based on this criterion.
} 
Table 5 Assessment of treatment alternatives.

\begin{tabular}{|c|c|c|c|c|c|c|c|c|c|c|c|c|}
\hline Stage & Criteria & Indicators & $\mathrm{C}^{\mathrm{a}}$ & BAT & vc & DAS & WAD & 1 & G & $\mathbf{P}$ & $\mathbf{L}$ & LB \\
\hline \multirow{14}{*}{ 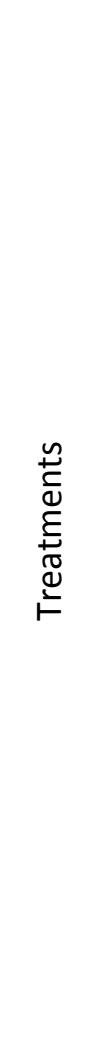 } & \multirow{4}{*}{ 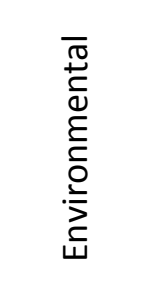 } & Greenhouse gas emissions $\left(\mathrm{kg} \mathrm{CO}_{2}\right.$-eq/t) [1] [2] [3] & -42 & -15 & -38 & -126 & -126 & -66 & -71 & -71 & 673.5 & 39.5 \\
\hline & & Soil occupation $\left(\mathrm{m}^{2} / \mathrm{t}\right)[4][5][6][7]$ & 0.8 & 0.8 & 7.63 & 1.29 & 1.29 & 0.1 & 0.1 & 0.1 & 3.22 & 3.22 \\
\hline & & Materials recovery (\% weight) [8] & 45 & 45 & 45 & 50 & 50 & 20 & 40 & 40 & 0 & 0 \\
\hline & & Odors & 3 & 3 & 3 & 3 & 3 & 1 & 1 & 2 & 5 & 4 \\
\hline & \multirow{4}{*}{ 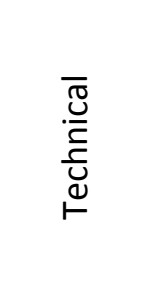 } & Energy produced (kwh/t) [8] & 0 & 0 & 0 & 889 & 889 & 750 & 555 & 555 & 0 & 55 \\
\hline & & Technological complexity & 2 & 2 & 2 & 3 & 4 & 4 & 4 & 5 & 2 & 3 \\
\hline & & Sensitivity of the process & 4 & 4 & 5 & 5 & 5 & 3 & 3 & 4 & 1 & 2 \\
\hline & & Energy consumption (kwh/t) [9] & 19 & 19 & 19 & 72 & 72 & 152 & 152 & 152 & 2 & 2,15 \\
\hline & \multirow{3}{*}{$\begin{array}{l}\bar{\pi} \\
\overline{0} \\
\stackrel{n}{n}\end{array}$} & Social Acceptance & 2 & 2 & 1 & 1 & 1 & 5 & 4 & 3 & 5 & 4 \\
\hline & & Occupational risks [10] & 4 & 4 & 3 & 2 & 2 & 4 & 4 & 4 & 5 & 4 \\
\hline & & Job creation (Job/1000t) [11] [6] & 0.4 & 0.4 & 0.5 & 0.33 & 0.1 & 0.1 & 0.1 & 0.1 & 0.1 & 0.1 \\
\hline & \multirow{3}{*}{ 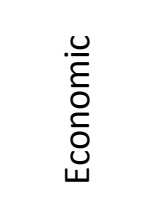 } & Investment costs ( $€ / t$-cap) [12] & 185 & 185 & $-\mathrm{b}$ & 487 & 205 & 472 & 575 & 575 & 77.78 & 104.4 \\
\hline & & Service costs ( $€ / t /$ year) [12] & 5.6 & 5.6 & $-{ }^{b}$ & 6 & 6 & 33.8 & 17.3 & 17.3 & 13.6 & 14.5 \\
\hline & & Economic remunerations $(€ / t)[13]$ & 1.65 & 1.65 & $-{ }^{b}$ & 11.13 & 11.13 & 32.64 & 25.68 & 25.68 & 0 & 3.97 \\
\hline & & & 0.61 & 0.61 & 0.44 & 0.67 & 0.66 & 0.43 & 0.50 & 0.52 & 0.33 & 0.42 \\
\hline
\end{tabular}

[1] (AEA, 2011); [2] (Chan et al., 2011); [3] (Smith et al., 2001)

[4] (Huerta et al., 2008); [5] (BINAS, 2014); [6] (COGERSA, 2014); [7] (G-advisory, 2015)

[8] (MMA, 2005); [9] (Hong et al., 2010); [10] (Barberá, 2011)

[11] (Friends of the Earth, 2010); [12] (Crowe et al., 2002); [13] (Milutinović et al., 2014)

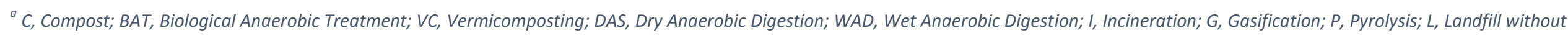
biogas use; $L B$, Landfill with biogas use. ${ }^{b}$ No information was found for this indicator. 
Table 6 Assessment of application alternatives.

\begin{tabular}{|c|c|c|c|c|c|c|}
\hline Stage & Criteria & Indicators & $\mathrm{CAS}^{\mathrm{a}}$ & BAS & EG & $\mathbf{D}$ \\
\hline \multirow{6}{*}{ 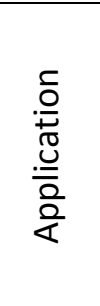 } & \multirow{2}{*}{ Environmental } & Improvement in soil conditions & 1 & 3 & 3 & 4 \\
\hline & & Emissions avoided & 2 & 3 & 1 & 4 \\
\hline & Technical & Required quality & 4 & 3 & 2 & 2 \\
\hline & Social & Involvement of users & 1 & 2 & 3 & 4 \\
\hline & \multirow{2}{*}{ Economic } & Demand & 1 & 2 & 1 & 4 \\
\hline & & Remunerations & 1 & 2 & 1 & 4 \\
\hline & & & 0.64 & 0.51 & 0.69 & 0.17 \\
\hline
\end{tabular}

${ }^{a}$ CAS, Compost Application in Soil; BAS, Biostabilized Application in Soil; EG, Energy Generation; D, Disposal. 


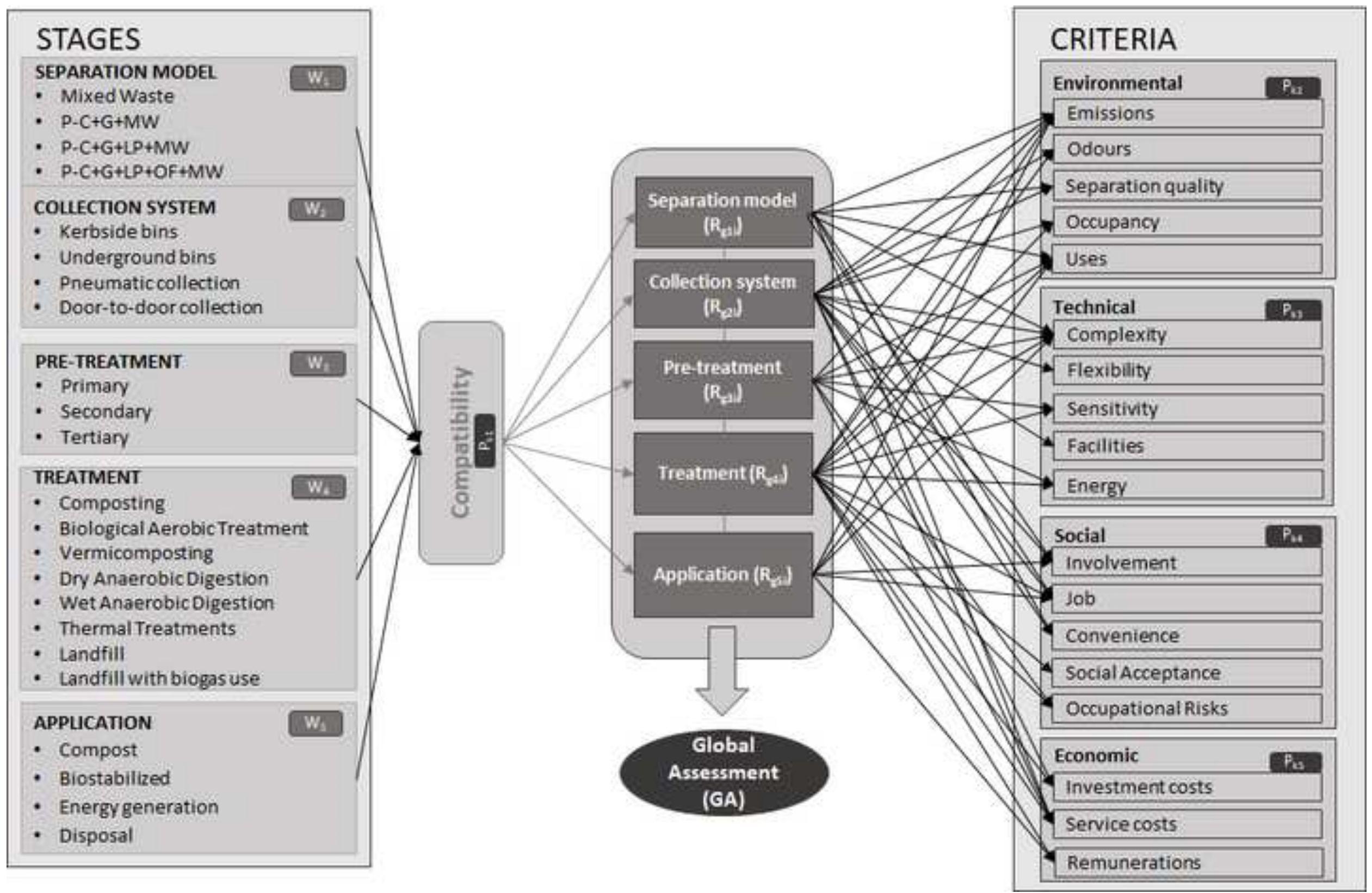


Click here to download high resolution image

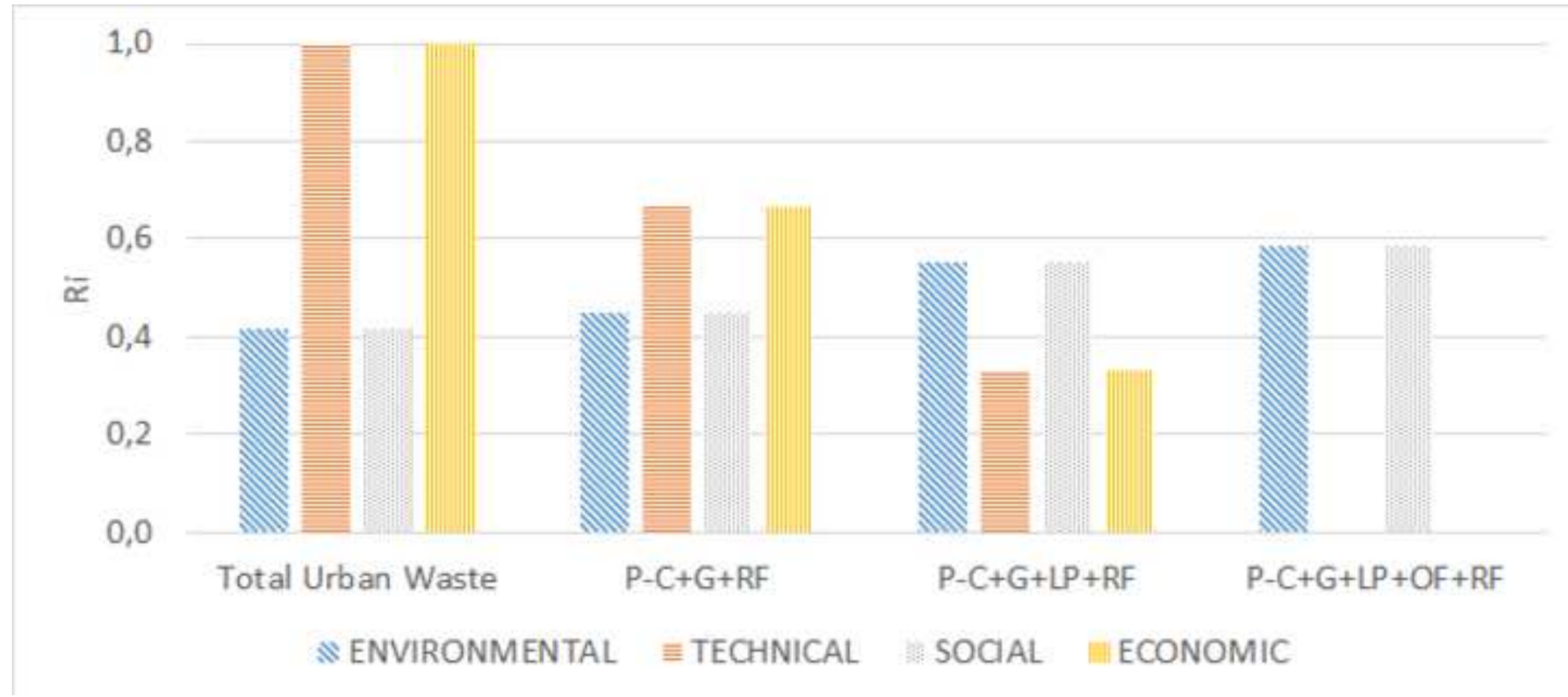


Figure 3
Click here to download high resolution image

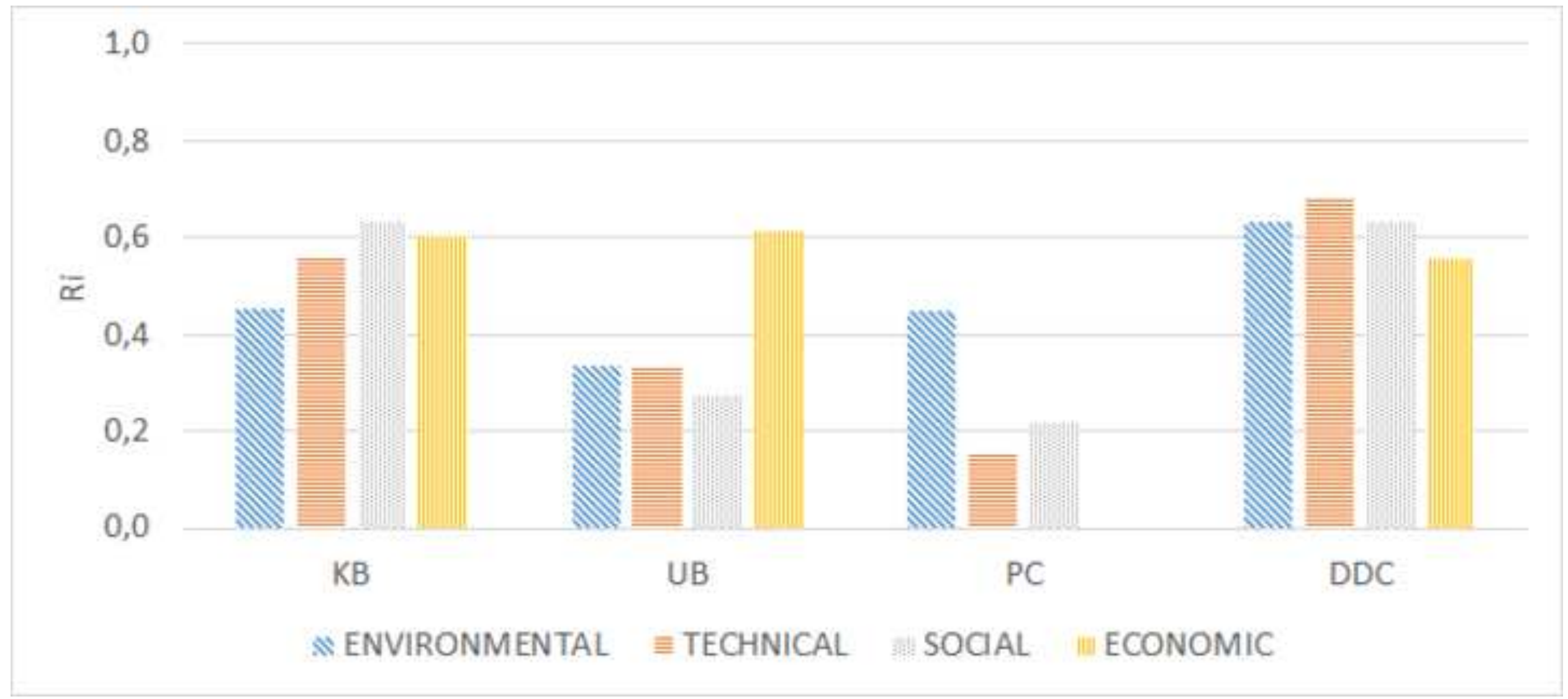


Click here to download high resolution image

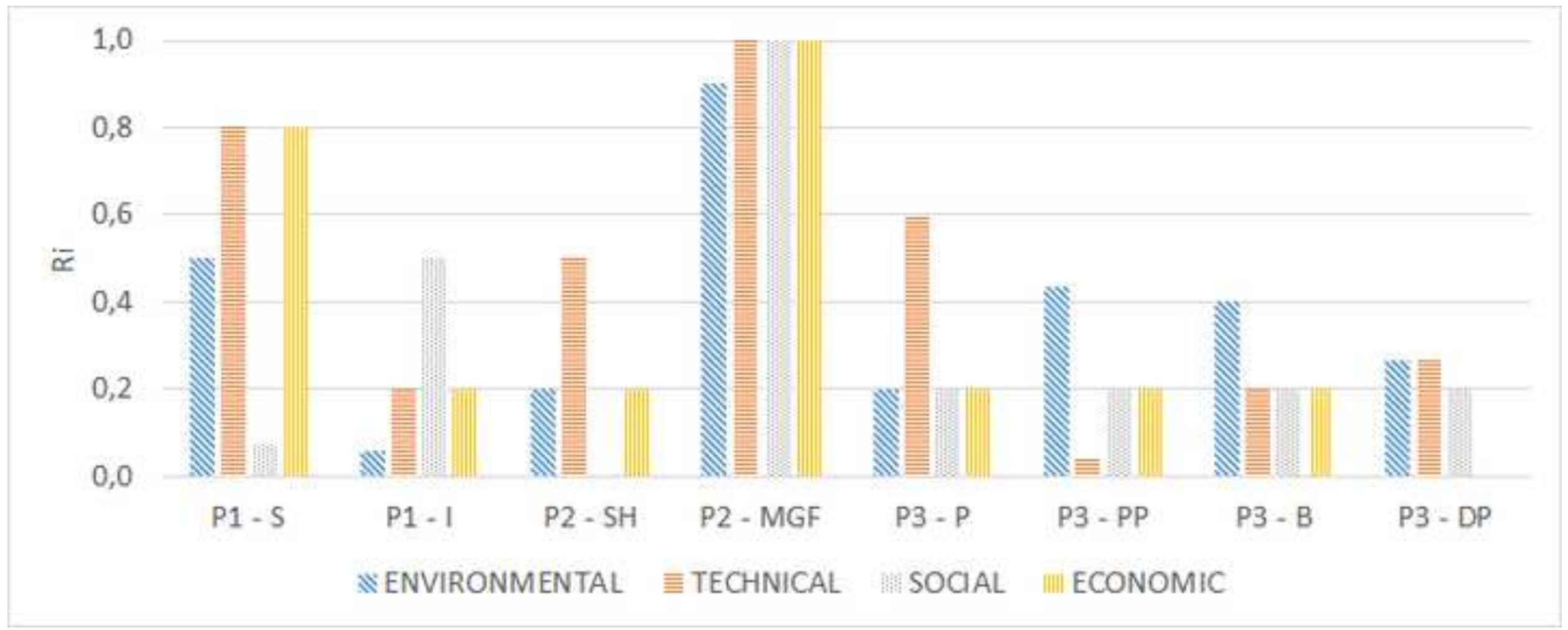


Click here to download high resolution image

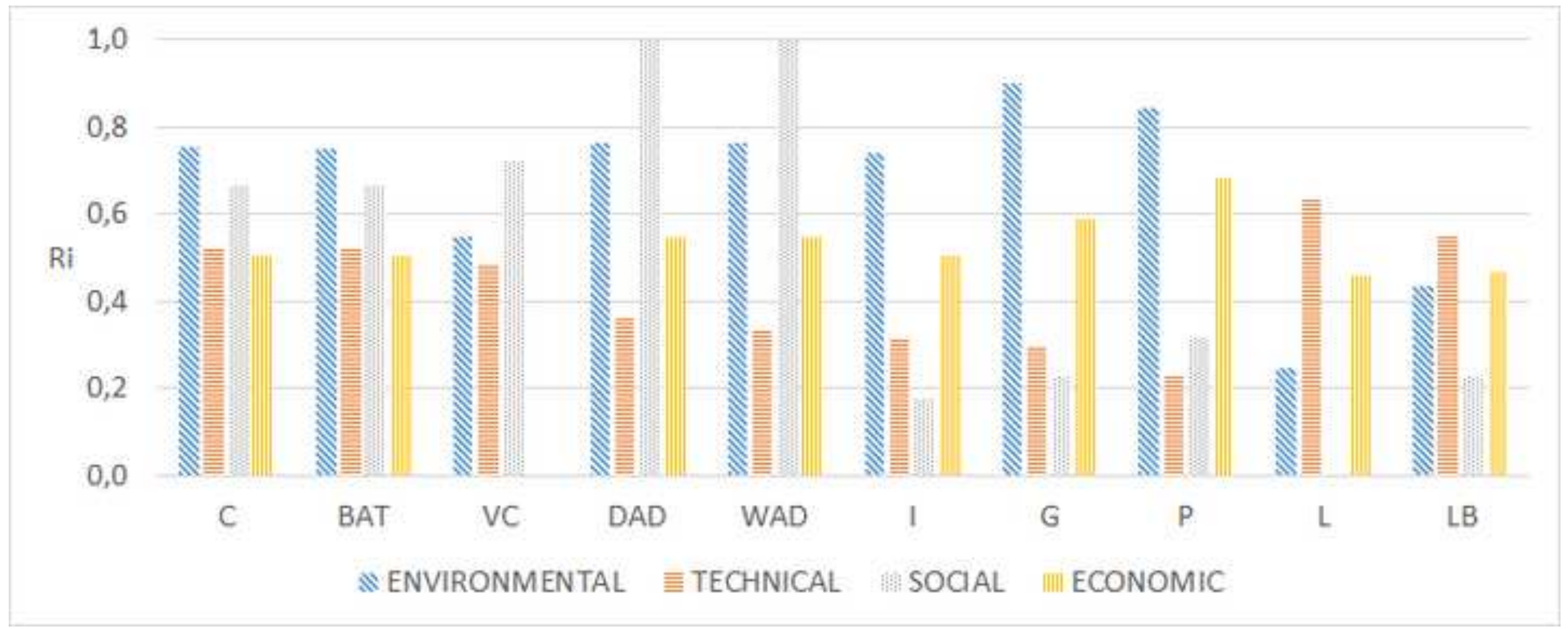




\section{Figure 6}

Click here to download high resolution image

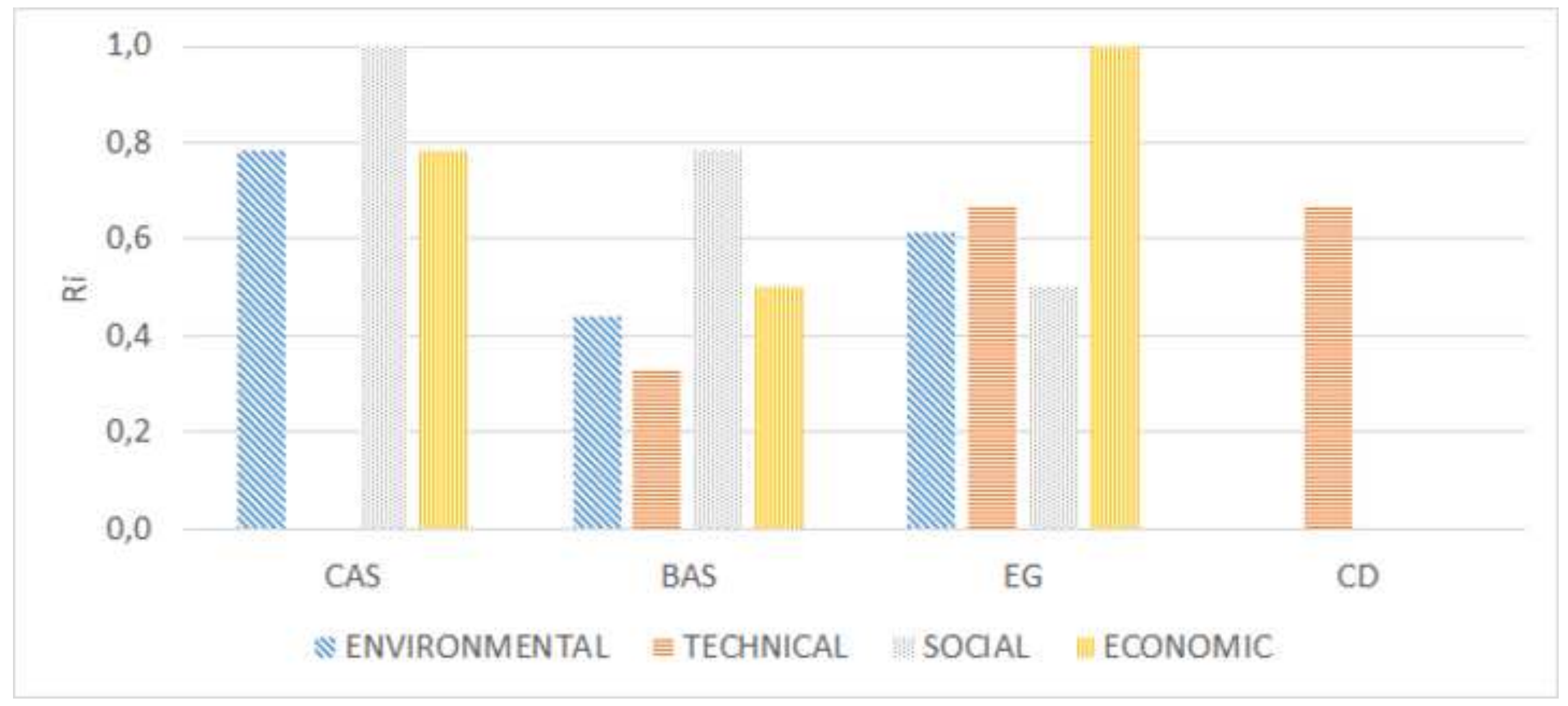




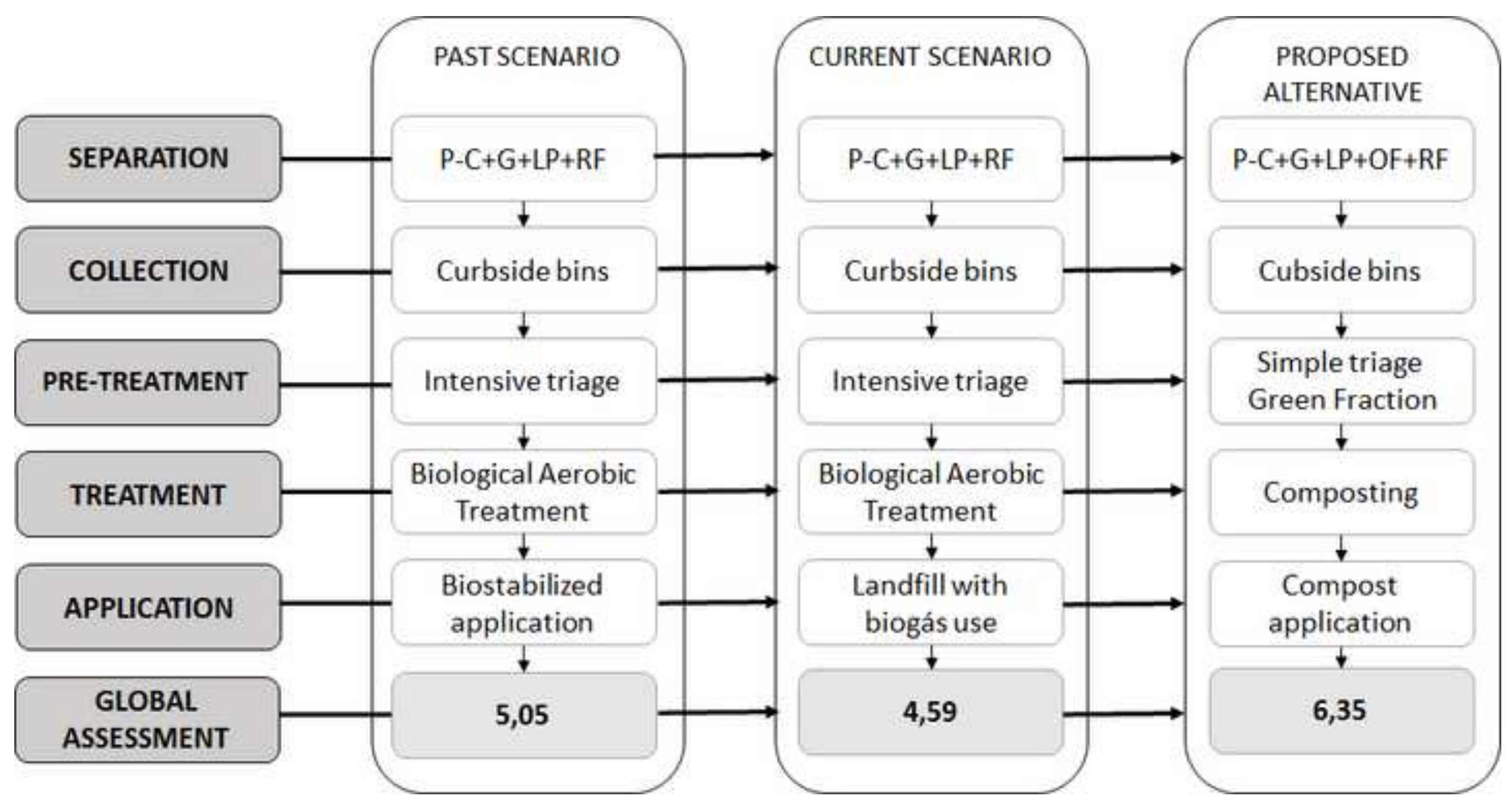


Click here to download high resolution image

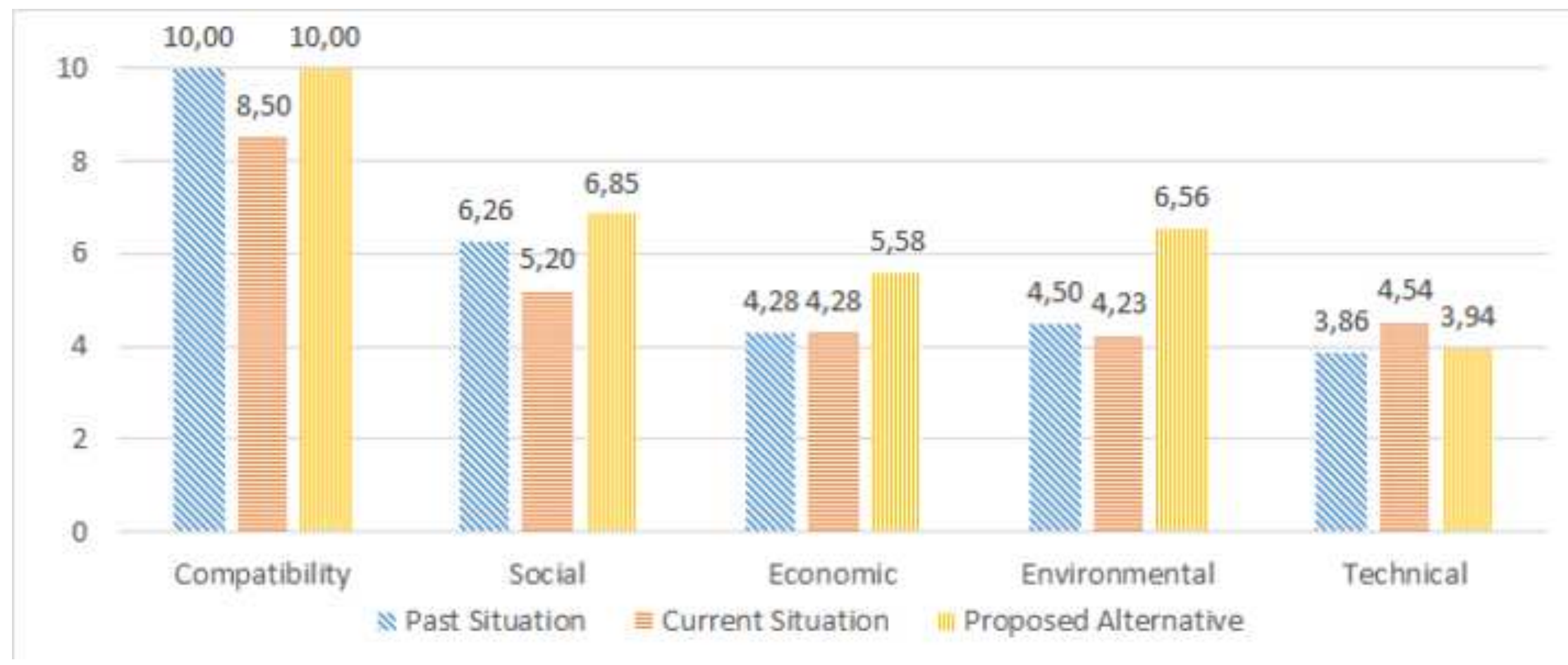

